\title{
A construção de vínculos político-territoriais na cidade: evidências de São Paulo
}

\author{
Telma Hoyler $^{1}$ (D) \\ Lucas Gelape 2 \\ Graziele Silotto $^{3}$ (i)
}

\begin{abstract}
Os legislativos municipais têm sido interpretados por meio de uma transposição teórico-argumentativa do cenário federal, tendo projetos de lei e o padrão de distribuição de votos como focos empíricos privilegiados para testar a hipótese distributivista. Porém, essas são proxies imperfeitas para testar a existência da atuação territorial de vereadores. Para investigar o tema, introduzimos de forma inédita a análise das indicações parlamentares em São Paulo, bem como seu estudo a partir de uma abordagem multimétodos, incluindo entrevistas em profundidade, observação participante e teste de hipótese de autocorrelação espacial local. Argumentamos que a atuação territorial de vereadores ocorre por meio de uma estrutura capilarizada de brokers, que alimenta e constrói vínculos ao longo de todo o mandato. Nada disso é capturável pelos métodos tradicionais que tratam do tema. Palavras-chave: brokers; vereadores; vínculo territorial; indicações parlamentares; legislativo municipal
\end{abstract}

\section{Introdução ${ }^{4}$}

O que fazem vereadores durante os três anos não eleitorais de seu mandato? Quem compõe um mandato parlamentar? Projetos de lei estão mesmo entre as prioridades de vereadores? Eles atuam de maneira territorializada ou procuram dispersar-se pela cidade e promover políticas difusas? De que maneira criam vínculos com os eleitores e quais

\footnotetext{
1 Universidade de São Paulo, Departamento de Ciência Política. São Paulo (SP), Brasil. E-mail: <telmahoyler@gmail.com>.

2 Universidade de São Paulo, Departamento de Ciência Política, São Paulo (SP), Brasil. E-mail: <lgelape@gmail.com>.

3 Universidade de São Paulo, Departamento de Ciência Política, São Paulo (SP), Brasil.

E-mail: <grazielesilotto@gmail.com>.

4 Os autores agradecem a Andréa Freitas, Jonathan Phillips, Eduardo Marques e Glauco Peres da Silva pelos comentários e sugestões recebidos em versões preliminares deste artigo, ao Centro de Estudos da Metrópole (Fapesp; processo número 2013/07616-7) pelo apoio institucional que nos possibilitou a conclusão do georreferenciamento e da categorização das indicações, e aos pareceristas anônimos da revista Opinião Pública pelos comentários e sugestões que resultaram na versão final. Agradecemos ainda à Fundação de Amparo à Pesquisa do Estado de São Paulo (Fapesp) pelo apoio (processo número 2017/05910-6) e à Capes e ao CNPq (processos número 140736/2017-4 e 169056/2018-0) pelas bolsas concedidas. Aprimoramentos necessários e eventuais equívocos são de nossa inteira responsabilidade.
} 
estratégias adotam para isso? Como sua atuação se relaciona à governança da cidade como um todo? Essas são algumas perguntas de uma agenda de pesquisa pouquíssimo explorada. Em parte, ela permanece inexplorada porque, além de raramente estudado, o funcionamento dos legislativos municipais tem sido interpretado à luz do caminho que a literatura de ciência política traçou para o cenário federal, como se a dinâmica local reproduzisse em miniatura processos que ocorrem naquele plano.

A literatura tem tradicionalmente abordado o tema da atuação dos vereadores por meio da análise de projetos de lei e do resultado eleitoral, associando votações médias dispersas dos eleitos (Gelape, 2017; Kinzo, Borin e Martins Jr., 2003) e destinação majoritária de projetos de lei previamente categorizados como "temáticos ou não particularizáveis" à ausência do trabalho territorial (Caetano, 2005; Silva, 2014). Essas pesquisas procuram questionar a hipótese distributivista, questão que orientou o debate sobre o Congresso Nacional brasileiro no final da década de 1990 e início da de 2000 . Partindo dessa transposição teórico-argumentativa e com base nessa metodologia, grande parcela dos trabalhos tem concluído, então, pela refutação de que vereadores direcionam suas ações a clientelas específicas. Tais pesquisas estão, evidentemente, concentradas no debate sobre os incentivos que as regras eleitorais e as instituições formais dos parlamentos geram sobre o comportamento dos parlamentares. Mas teriam esses modelos incluído todas as variáveis relevantes? Em outros termos: se ampliarmos o escopo das variáveis para outras instituições/instrumentos/interesses desses atores e mudarmos a metodologia para um conjunto de métodos que nos permita enxergar a realidade de uma forma mais abrangente, as conclusões serão as mesmas?

Caminha paralelamente a esse debate, pela abordagem norte-americana da rational choice, a discussão sobre clientelismo. Focada no efeito da distribuição de políticas sobre voto, essa literatura tem argumentado pela existência de padrões clientelistas na distribuição de políticas, em especial em países da África e da América Latina. Esses são continentes bastante privilegiados nas análises, uma vez que está nos pressupostos desse debate que o fenômeno seria uma característica de países pobres. Embora desconsidere todo o avanço teórico sobre como políticas públicas são implementadas e tenha forte viés normativo, essa literatura avançou na introdução de brokers como atores políticos que conectam eleitos e eleitores.

De um lado, temos, então, uma importante parcela do debate sobre instituições eleitorais e legislativas questionando a tese da proximidade entre eleitores e eleitos. De outro, a discussão sobre clientelismo postula a existência dessa proximidade. E, no meio, as perguntas que dão início a este artigo permanecem intocadas. Parece-nos haver, portanto, uma lacuna teórica a ser enfrentada por meio de novas formas de investigação empírica.

Evidentemente, uma agenda de pesquisa não se resolve com um ou poucos artigos, mas é nessa direção que procuramos avançar. Em termos macroanalíticos, este artigo aponta novos caminhos na investigação que a ciência política faz sobre legislativos 
municipais de grandes cidades. Em termos mesoanalíticos, procuramos mostrar como a atuação dos vereadores e a relação que criam com o eleitorado ocorrem por intermédio de brokers e, em termos microanalíticos, apresentamos como brokers operam por meio do instrumento das indicações parlamentares. Nosso argumento geral é que as relações entre os vereadores e os eleitores são mediadas pelos brokers, e que a atuação destes é territorialmente localizada, de forma que eles constroem vínculos político-territoriais com os eleitores no espaço urbano. Indicação parlamentar é um instrumento que possibilita a construção desses vínculos a depender de como é mobilizado e nos permite olhar para além tanto do momento eleitoral quanto dos projetos de lei.

O artigo está estruturado em três partes principais, além desta breve introdução e das "Considerações finais": a primeira seção, "O que já sabemos e para onde vamos", mergulha no percurso teórico que tem tematizado o tema dos vereadores e brokers; a segunda seção, "Metodologia" apresenta a metodologia multimétodo desta pesquisa e a base inédita de indicações parlamentares; e a terceira seção, "As indicações parlamentares na cidade de São Paulo", mostra as evidências da pesquisa propriamente dita, ou seja, uma incursão qualitativa sobre o que são e como funcionam as indicações paulistanas a partir da atuação do broker, combinada com uma análise de evidências quantitativas sobre o uso e a distribuição espacial das indicações na cidade de São Paulo.

\section{O que já sabemos e para onde vamos}

A semelhança entre os níveis federal e local quanto às características de ordem institucional-legal tem sustentado o transplante automático do enquadramento teórico de um nível a outro: como o sistema eleitoral e as regras gerais de funcionamento do Legislativo são os mesmos, esperam-se também os mesmos incentivos aos parlamentares em termos da relação com o Executivo e com os eleitores. Assim, os poucos estudos dedicados a compreender a relação Executivo-Legislativo em contextos estaduais e municipais o fizeram desconsiderando, na maior parte dos casos, as especificidades das instituições, dos atores e dos processos políticos locais, permanecendo de maneira proeminente a clivagem dicotômica adaptada da discussão travada desde os anos 1990 no plano federal a respeito do impacto de nossas instituições sobre a governabilidade.

O debate é antigo e conhecido. Grosso modo, de um lado, somam-se pesquisas sobre o sistema de escolha dos legisladores e seu efeito paroquialista a partir de estratégias para conquistar eleitores (Ames, 1995, 2003; Mainwaring, 2001) e, de outro lado, trabalhos criticam a ausência de evidências empíricas sobre a orientação paroquialista e dedicam-se a entender o efeito dos partidos sobre o comportamento dos parlamentares no Congresso Nacional, o que garantiria a governabilidade do incumbente no Executivo e constrangeria os incentivos à agência personalista (Figueiredo e Limongi, 1999).

No âmbito municipal, do lado que enfatiza o papel personalista dos vereadores no caso paulistano, encontramos argumentos como o de Neto (2003), para quem o vereador, 
assim como os parlamentares federais, não se percebe eleito para controlar o governo ou governar, de modo que sua imagem poderia ser traduzida como a de uma caricatura de assistente social com poderes especiais. Para o autor, o arcabouço institucional erguido após a Constituição de 1988, que centralizou poderes nas mãos do chefe do Executivo e dispersou o número de partidos devido à fórmula eleitoral proporcional de lista aberta, é a razão da fraqueza do parlamento e do papel clientelista e fisiológico desempenhado pelos vereadores.

De outro lado, Kinzo, Borin e Martins Jr. (2003) refutaram a hipótese distributivista ao examinar os padrões de competição eleitoral nos distritos administrativos da cidade de São Paulo a partir dos votos obtidos nas eleições de 1992, 1996 e 2000. Considerando como base eleitoral concentrada os candidatos que tiveram mais de $50 \%$ dos votos em até seis distritos contíguos, concluem que existe o predomínio de representantes com base eleitoral dispersa. Isto é, não existiria a "distritalização informal" necessária para as hipóteses distributivistas. Seguindo outra linha investigativa, mas traçando conclusões que se aproximam, Caetano (2005) buscou aplicar o modelo de análise de Figueiredo e Limongi (1999) a São Paulo ao examinar os projetos de lei aprovados entre 2001 e 2004. O autor concluiu que o Executivo possui fortes instrumentos de coordenação que propiciam não só a aprovação de suas matérias, mas uma aprovação mais rápida, e que não existe respaldo empírico para a tese da primazia das iniciativas de caráter não programático e que os vereadores focam suas ações na política social de maneira difusa. Conclusão semelhante teve Silva (2014) ao analisar as propostas de legislação encaminhadas pelos vereadores à mesa da Câmara Municipal de São Paulo no período entre 2001 e 2008. Dos 5.383 projetos analisados, apenas $1,3 \%$ foi destinado ao que ele considerou regiões específicas do município, apontando, mais uma vez, para a inexistência da conexão eleitoral, ou seja, para a rejeição da hipótese distributivista.

Diversas críticas ao modelo distributivista já foram realizadas por autores da teoria centrada nos partidos, que, por seu turno, avançou consideravelmente ao introduzir a forma como se organiza o processo decisório nos parlamentos como variável analítica fundamental. Ainda assim, ambos os lados do debate desconsideram, para a análise da relação candidato-eleitor, elementos que vão além da atividade de legislar e dos seus aspectos formais.

Pesquisas recentes têm demonstrado que o trabalho dos vereadores não se resume apenas ao processo de produção de legislação ordinária. Por meio de um survey realizado com 422 vereadores de 44 municípios mineiros, Rocha e Silva (2017) encontraram, por exemplo, que mais de $50 \%$ consideram que a função mais importante no exercício do mandato é resolver os problemas do município ou do bairro, contra apenas $17 \%$ que consideram em primeiro lugar a elaboração legislativa como principal atividade desempenhada pelo vereador. Ao apresentar um detalhamento da investigação da mesma 
amostra5, Bastos (2017) obteve achado semelhante. Apenas 3,8\% dos vereadores declararam que a principal forma de atender aos eleitores que os procuram é por meio da apresentação de um projeto de lei. Antes disso aparecem as indicações ou requerimentos, com 33\% das respostas e, em seguida, a busca de ajuda direta com prefeito, secretários ou funcionários da prefeitura $(26,4 \%)$ e o encaminhamento para órgãos competentes $(18,3 \%)$. É curioso notar como ainda assim é a produção legislativa ordinária que permanece sendo objeto empírico privilegiado nas principais análises em relação a esse tema. Todo o resto das atividades é frequentemente enquadrado como "clientelismo" ou "paroquialismo", termos que aparecem muitas vezes mais como adjetivação normativa do que como conceito.

Ao privilegiar o enfoque das instituições formais que balizam a relação entre Executivo e Legislativo no âmbito federal, o debate brasileiro acabou por desviar-se das investigações sobre como funciona, na prática, a relação territorial entre eleitor e representante e consolidou-se pela negação de tal proximidade. O exame do tema em nível federal foi feito, sobretudo, pela análise da destinação de projetos de lei (Ricci, 2006; Amorim Neto e Santos, 2003) e emendas ao orçamento público (Firpo, Ponczek e Sanfelice, 2015; Pereira e Mueller, 2003; Limongi e Figueiredo; 2005; Mesquita, 2008; Mesquita et al., 2014; Vasselai e Mignozzetti, 2014), sendo também reproduzido para a cidade de São Paulo, como vimos. De modo geral, tais testes partem do pressuposto de que, quanto mais individualizáveis e mais concentrados territorialmente forem os projetos ou emendas e quanto mais concentrados os votos dos parlamentares, mais "personalista" ou "clientelista" será o parlamentar. Com base na categorização prévia do que é considerado individualizável e concentrado, esses estudos concluem, de modo geral, que tal não é o padrão no caso brasileiro, ou seja, não há indícios nas instituições legislativas sobre o uso predominante de estratégias clientelistas dos parlamentares (a hipótese distributivista).

Enquanto a principal parcela do debate nacional refuta, portanto, a proximidade entre parlamentares e eleitores pela conexão eleitoral, o debate sobre clientelismo produzido pela rational choice norte-americana sobre a América Latina especifica o que entende por clientelismo de uma maneira diferente do argumento da conexão eleitoral. Ainda assim, mantém como fato consolidado que o sucesso da distribuição de políticas com vistas ao voto ocorre por uma infraestrutura organizacional de brokers que operam próximos aos eleitores, conectando-os aos políticos (Kitschelt, 2000; Stokes et al., 2013; Oliveros, 2016).

Brokers são caracterizados pela literatura como lideranças locais, ativistas, moradores, funcionários de partidos, líderes comunitários ou até mesmo vereadores/prefeitos que se situam entre a política institucional e os cidadãos em geral. Possuem um papel central seja na implementação de políticas, ao proporcionar o acesso

\footnotetext{
5 Pesquisa "Representação política no nível municipal no Brasil", conduzida pelo Núcleo de Estudos sobre Política Local (Nepol/UFJF). Para mais informações sobre a pesquisa citada, ver Bastos (2017).
} 
de cidadãos a determinados recursos, seja na conquista de fatias do eleitorado (Stokes et al., 2013; Novaes, 2018). Isso se dá pela construção de relações de confiança que brokers conseguem estabelecer com eleitores, de forma a conseguirem informações sobre suas demandas e eventualmente atendê-las em busca do voto.

Nas interpretações da ciência política, os brokers se fazem presentes em dois momentos. O primeiro deles é o momento eleitoral, especialmente na conquista do eleitorado em prol de determinados candidatos/políticos; ao passo que o segundo é aquele em que há atuação desses intermediários entre eleições, facilitando o acesso a serviços públicos e supostamente monitorando os representados.

O momento eleitoral é, de longe, o mais explorado pela literatura (Stokes et al., 2013; Lima, 2016; Novaes, 2018). Por meio de promessas de políticas futuras ou de compra de votos (Brusco, Nazareno e Stokes, 2004; Finan e Schechter, 2012; Nichter, 2018; Schaffer e Baker, 2015), o broker é quem leva aos cidadãos tudo aquilo que corresponde à esfera política formal. Esse modelo pressupõe que, em troca, os eleitores votariam em quem o broker apresenta como fiador da promessa, do financiamento ou da promoção da política em questão. Essa relação é identificada como clientelista se a "distribuição de políticas" ocorre com base em políticas não programáticas, entendidas por programáticas aquelas que possuem critérios de distribuição claros e publicizados, aplicando-se o critério da condicionalidade do voto, nos termos descritos por Stokes et al. (2013, p. 8).

Dada a sua vinculação com o conceito de clientelismo, a atuação do broker vem quase sempre carregada de um sentido normativamente negativo, relacionado à desvirtuação da política, que geraria, por exemplo, impactos negativos para relações de accountability (Gallego, Li e Wantchekon, 2018), já que o eleitor ficaria confuso sobre quem ele deve cobrar ou de quem ele deve esperar policies - do broker ou do político? Ou geraria ainda o que Stokes (2005) chamou de accountability perversa, em que o político exerce controle sobre o eleitor e não o contrário. Tais relações clientelistas, como criticou Hagopian (2009), seriam consideradas características de países pobres e/ou democracias emergentes, fechando um ciclo negativo que retroalimentaria os problemas políticos, sociais e econômicos dos países. De acordo com Stokes, a própria definição de clientelismo aponta para a pobreza do cliente ${ }^{6}$. Isso é justificado pela aversão ao risco, maior entre pobres que entre ricos; pela preferência por recompensas imediatas, em vez de políticas programáticas, que poderão nunca ser cumpridas (Kitschelt, 2000); e pelo ganho marginal na distribuição de recursos, que é maior para pobres do que para ricos (Calvo e Murillo, 2004; Kitschelt e Wilkinson, 2007; Dixit e Londregan, 1996).

Uma análise mais abrangente, menos normativa e que expande a análise da atuação dos brokers para além do momento eleitoral foi desenvolvida por Zarazaga (2014)

\footnotetext{
6 "(...) the very definition of clientelism points toward the poverty of the client. Indeed, it is impossible to survey the qualitative literature on political clientelism without concluding that it is a feature disproportionately of poor countries" (Stokes, 2005, p. 217).
} 
e Ayuero (1999, 2000) para o caso de cidades argentinas. Nesses trabalhos, os brokers aparecem como atores que, em geral, residem no local em que atuam e constroem vínculos com a população pela proximidade cotidiana. Zarazaga (2014) enfatiza que a própria viabilidade da política e da governança nas cidades dependeria desses intermediadores, uma vez que é pela proximidade com os eleitores/cidadãos que eles podem intervir no poder público. O trabalho desses intermediários vai desde a construção de redes locais, nas quais os brokers são responsáveis por mediar a relação entre seus chefes políticos e os eleitores, passando por uma esfera de governança, na qual ajudam na entrega de serviços públicos durante todo o período de mandato e resolvem problemas de pequena escala dos moradores (como iluminação pública, poda de árvores, pontos de ônibus etc.), até a promoção da eleição de seus chefes políticos.

Zarazaga (2014) argumenta que esses atores realizam essas múltiplas tarefas porque sua eficácia (do ponto de vista do político) depende de que eles estejam sempre presentes no cotidiano local dos moradores que almejam fidelizar. São eles que resolvem pequenos problemas nos bairros/comunidades e conseguem acesso a recursos públicos, e somente na medida em que eleitores veem os retornos às suas demandas é que confiam no broker. E, apenas assim, eles são capazes de munir políticos de informações relevantes, em relação tanto ao aspecto eleitoral quanto à provisão de determinadas políticas públicas onde elas são necessárias.

Em comparação à abordagem da rational choice focada no momento eleitoral, Zarazaga aporta uma visão mais abrangente sobre as relações de brokerage, já que, além de provedores de votos para seus chefes políticos, tais atores são analisados também como aqueles que intervêm junto ao poder público e proveem benesses essenciais à vida cotidiana das pessoas, permitindo, assim, que o Estado chegue até elas. O que é visto como uma mera questão de "distribuição de políticas" no primeiro enfoque ganha maior complexidade pela consideração de que as políticas não estão simplesmente prontas, mas são construídas ao longo de sua implementação, como a vasta literatura sobre políticas públicas vem trabalhando desde a década de 1970 (Pressman e Wildavsky, 1973; Gun, 1978; Gun e Hogwood, 1982). A atuação dos brokers constrói não apenas uma estrutura que possibilita relações eleitorais, mas também estruturas relacionadas à entrega de políticas públicas aos cidadãos, uma vez que são eles que adentram lugares pouco ou até mesmo não acessados pelo Poder Executivo. Embora o autor afirme que essa atuação configura pork barrel, ela não seria clientelista, pois não conta com o componente discricionário para a definição de quem serão os beneficiários (a condicionalidade), baseado no suporte político individual.

Além de atribuírem normativamente o termo clientelismo aos países em desenvolvimento e de ignorarem o processo envolvido na implementação de políticas, os estudos sobre clientelismo em cidades brasileiras que partem da abordagem rational choice (Nichter, 2018; Frey, 2019) também têm muitas vezes feito generalizações para o Brasil com base em cidades do Nordeste agrário, ignorando as diferenças de dinâmica entre rural 
e urbano, assim como características próprias do nível municipal. Ademais, não incluem de maneira estruturante os brokers na compreensão do fenômeno.

São poucos e ainda isolados os trabalhos existentes sobre brokers no caso brasileiro. As pesquisas apontam para a importância dos políticos locais como brokers de políticos nacionais. Ames (1995) já identificava os prefeitos como cabos eleitorais de candidatos à presidência. Barone (2014) expandiu a análise de Ames longitudinalmente e incluiu demais cargos legislativos, encontrando alguns resultados nesse sentido no caso brasileiro. Novaes (2018) se alinha a tal visão e aponta o caso dos partidos que buscam brokers entre pessoas localmente conhecidas, como líderes comunitários, burocratas locais, caciques ou ainda políticos locais. Lima (2016) também reforça o caso dos prefeitos como brokers de parlamentares, configurando o que chamou de committed brokers. Em suma, para essa literatura, políticos locais seriam responsáveis pela provisão de palanques eleitorais para candidatos das disputas nacionais e garantiriam votos locais aos políticos da esfera nacional. Mais uma vez, o nível local não é analisado detidamente e o momento eleitoral é o privilegiado.

O estudo de como indicações são criadas e utilizadas por meio de uma abordagem multimétodos, foco do presente artigo, traz pelo menos três vantagens: (1) leva-nos a pensar a função dos brokers não apenas como o elo entre o plano federal e o municipal como eles têm sido observados no Brasil -, mas também como agentes que exercem poder conectando a si mesmos e os vereadores aos eleitores e territórios da cidade; (2) privilegia os demais três anos de mandato que não o ano eleitoral, o qual tem balizado o debate da conexão eleitoral; (3) avança no detalhamento de como essa vinculação acontece.

Em relação ao clientelismo, considerando o percurso que a literatura adotou, tal termo não poderia ter sido omitido na construção de um argumento e de uma revisão teórica que inclui poderes, parlamentares, eleitores e territórios, e por isso foi mencionado. Propomos, contudo, um passo atrás, que consiste em suspender a aplicação direta da normatividade implicada nas principais teorias em voga e iniciar um movimento dedutivoindutivo de compreensão da construção desses vínculos. Isto é, informados pela teoria, mas sem deixar que ela limite nossa compreensão mais profunda do fenômeno. Se a existência de clientelismo puder ser derivada, por exemplo, dos critérios de entrega de uma política, será preciso então compreender como tais critérios são formados e como a política é implementada, e isso foge ao escopo deste artigo. Nosso argumento principal é que as relações entre os vereadores e os eleitores são mediadas pelos brokers, cuja atuação se dá por meio da construção de vínculos político-territoriais com os eleitores no espaço urbano. Indicação parlamentar é um instrumento que possibilita a construção desses vínculos e que nos permite olhar além tanto do momento eleitoral quanto dos projetos de lei.

Para mergulhar nessa tarefa, o presente artigo enfoca o município de São Paulo, tendo em vista o casamento entre a lacuna de estudos similares, a importância em compreender a dinâmica municipal de maneira detida (Marques, 2017) e a disponibilidade 
de dados que permitam olhar para essa dinâmica de maneira abrangente. Os argumentos aqui presentes são potencialmente generalizáveis a outras cidades que adotem regras (sistema eleitoral), instrumentos (indicações, requerimentos e afins) e instância de poder (descentralização territorial municipal, como subprefeituras) semelhantes. Nesse sentido, embora genericamente falemos do "nível municipal", é na dinâmica de grandes cidades brasileiras (em termos populacionais) que possivelmente encontraremos casos semelhantes. Em cidades pequenas, ainda que conte com uma equipe de assessoria, o próprio vereador consegue atender às demandas dos eleitores pessoalmente. Assim, este artigo inicia essa agenda de pesquisa para o caso paulistano por meio da exploração do uso de indicações pelos vereadores paulistanos. Como veremos, indicação é um instrumento legislativo de uso facultativo pelo qual o vereador pode demandar ações ao Executivo. Nesse sentido, somamos esforços aos recentes trabalhos que problematizam a análise de projetos de lei como principais preocupações dos vereadores (Rocha e Silva, 2017) e que utilizam informações quantitativas sobre indicações nas cidades do Rio de Janeiro e Salvador (D'Ávila, Cerqueira Lima e Jorge, 2014; Rangel, 2014).

\section{Metodologia}

Este artigo utiliza uma combinação de métodos qualitativos e quantitativos. Para compreender o que são indicações e como são utilizadas, acompanhamos ${ }^{7}$, entre julho de 2018 e agosto de 2019, o cotidiano de dois brokers de partidos distintos (Antônio, centrodireita, e Júlio, centro-esquerda) por meio de uma observação participante (Schwartz-Shea e Majic, 2017). Além disso, para explorar a possibilidade de generalizações a partir da observação participante, triangular informações e obter uma compreensão mais aprofundada do fenômeno, realizamos entrevistas com burocratas do Executivo (4) e assessores e vereadores de diferentes partidos (14 assessores e 5 vereadores). Embora não tenhamos o objetivo de elaborar conclusões por partido, buscamos obter certa diversidade no espectro ideológico, a qual foi condicionada, pela natureza do método, à disponibilidade dos interlocutores em nos receber. Adicionalmente, a escolha dos parlamentares foi também condicionada pela atuação em territórios distintos da cidade, de maneira a minimizar os dilemas éticos para os pesquisadores. Ao longo de todo o texto, alteramos nomes, partidos, endereços, número de documentos e datas de modo a preservar nossas fontes.

Para a análise quantitativa das informações, utilizamos um banco de dados inédito construído com todas as indicações produzidas por vereadores paulistanos entre os anos de 1991 e 2012. Ao todo, esse banco de dados é composto por 92.959 observações, correspondentes a cada indicação emitida e protocolada na Câmara Municipal de São Paulo

\footnotetext{
7 Telma Hoyler, coautora deste artigo, realizou o acompanhamento e as entrevistas como parte de sua pesquisa doutoral, em processo de finalização.
} 
nesse período. Para trabalharmos somente com legislaturas inteiras, este artigo restringe a análise ao período entre 1993 e 2012, abrangendo cinco legislaturas e totalizando 89.891 observações. O banco foi coletado com as seguintes informações: número, ano, ementa, órgão destinatário, motivo, endereço, administração regional destinatária, bairro, vereador autor da indicação e partido. A partir do endereço informado, utilizamos um sistema de captura automática de coordenadas a partir de endereços para georreferenciar essas indicações. Esse processo foi bem-sucedido para um total de 75.277 observações $^{8}$, ou seja, cerca de $84 \%$ das indicações das cinco legislaturas analisadas.

Realizamos duas análises principais desses dados de indicações. Primeiramente, fizemos uma exploração da sua distribuição ao longo dos anos e das legislaturas, identificando padrões e categorizando os vereadores a partir do volume de indicações emitidas por cada um deles nesses dois intervalos de tempo diferentes. Além disso, dado o argumento de atuação territorial dos brokers, realizamos testes de autocorrelação espacial local (Moran Local) para investigar a existência de clusters de maior propositura de indicações por cada vereador (a cada legislatura).

\section{As indicações parlamentares na cidade de São Paulo}

Esta seção apresenta as evidências da pesquisa construída com base na metodologia acima explicitada. Inicialmente, descrevemos o que são as indicações e como elas tramitam entre os órgãos públicos. Em seguida, descrevemos como os vereadores as utilizam ao longo dos anos, destacando que há variação na quantidade de indicações emitidas por cada um deles. Entrando em nosso argumento principal, a subseção seguinte apresenta como elas se distribuem pelo espaço, destacando a existência de formação de clusters de áreas com volume alto de indicações em um contingente expressivo dos vereadores que propuseram ao menos 30 delas numa legislatura (esse recorte corresponde a $53,1 \%$ dos pares de vereador-legislatura em nosso banco de dados). Em seguida, demonstramos como as indicações nascem nos territórios e têm sua tramitação acompanhada pelos brokers. Por fim, esboçamos um argumento sobre como isso se relaciona ao momento eleitoral, a ser aprofundado por pesquisas futuras.

\section{O que são e como tramitam}

Indicação é um instrumento legislativo de uso facultativo pelo qual o vereador pode demandar ações ao Executivo, sem a força legal de um projeto de lei, e que não precisa ser submetido a um processo de aprovação no plenário da Câmara. Como o regimento interno da Câmara Municipal de São Paulo (CMSP) é bastante vago na regulamentação

\footnotetext{
${ }^{8}$ A geocodificação foi realizada utilizando-se a API do Here Geocoder, a partir da busca pela combinação de endereço, bairro/subprefeitura, cidade e estado de cada indicação.
} 
desse instrumento, limitando-se a defini-lo em um único artigo ${ }^{9}$, diferentes caminhos operacionais são possíveis em sua tramitação. Alguns vereadores optam por encaminhar as indicações ao poder Executivo por meio da burocracia da CMSP, enquanto outros o fazem sem registrá-las institucionalmente, mas pela atuação dos brokers, que entram diretamente em contato com burocratas do Executivo responsáveis por encaminhar a demanda ou resolver o problema. Muitos dos mandatos ${ }^{10}$ optam pelas duas formas, a depender do pedido em questão.

Há diferentes razões para os mandatos parlamentares operarem de uma forma ou outra. Aqueles que encaminham formalmente as indicações podem estar procurando respaldo institucional a um pedido ou, até mesmo, não ter real preocupação/interesse em resolver a demanda em questão. Isso porque a via formal implica um encaminhamento de ofícios pela burocracia, que, sem o devido acompanhamento, pode facilmente se perder ao longo dessa cadeia. Ainda assim, caso essa solicitação tenha sido formalizada, o vereador ou broker pode informar ao eleitorado que "o pedido foi encaminhado", ainda que se omita da responsabilidade pela condução da questão. Um dos motivos para o envio direto das indicações ao Executivo pode estar ligado a uma tentativa de o gabinete do vereador agilizar a condução da demanda, beneficiando-se de contatos com burocratas e secretários construídos ao longo de suas carreiras.

Por meio de indicações, os parlamentares enviam sugestões na forma de ofícios de prestação de serviços específicos ao Executivo. Elas podem incluir desde questões mais pontuais de zeladoria urbana, como pavimentação, tapa-buraco, limpeza urbana, sinalização de rua e iluminação pública, até aquelas que exigem planejamento de mais longo prazo, como extensão da rede de assistência, saúde e educação. São sempre demandas de benefícios localizados, porém não individualizáveis. A partir das indicações, os vereadores esperam ser associados a benefícios tangíveis aos eleitores. Essa associação ocorre por meio de uma estrutura de brokers que atuam territorialmente, atores fundamentais para a compreensão da política urbana, como veremos adiante.

Somente as indicações encaminhadas ao Executivo pela burocracia da CMSP compõem a base de dados que utilizamos no presente artigo. Portanto, essa base subestima o total de indicações realizadas por vereadores paulistanos. Embora isso seja potencialmente problemático para extrair conclusões sobre o conteúdo das indicações em si, encontramos que cerca de $70 \%$ dos vereadores ${ }^{11}$ em cada uma das legislaturas analisadas protocola as indicações institucionalmente via CMSP (embora não necessariamente o façam de maneira exclusiva), o que nos sugere que as afirmações desta

\footnotetext{
9 O artigo 219 da Resolução no 2, de 26 de abril de 1991, prevê apenas que "indicação é a proposição em que o vereador sugere aos poderes competentes medidas de interesse público".

10 Chamamos de "mandato" o projeto político e os atores que se organizam em torno de um gabinete parlamentar. Essa distinção é importante, pois há pessoas que estão no mandato, mas não estão formalmente na estrutura do gabinete. O termo é também utilizado para designar o período de quatro anos em que o vereador ocupa o cargo, mas essa diferença pode ser identificada pelo contexto da frase.

11 Uma vez desconsiderados os suplentes.
} 
pesquisa têm potencial para se aplicar à população dos vereadores. Assim, em conjunto com a análise qualitativa, essas informações nos possibilitam compreender o funcionamento da dinâmica espacial de atuação dos mandatos, ainda que não nos permitam fazer inferências quantitativas sobre todas as indicações produzidas na cidade no período analisado. No Gráfico 1 , vemos o número absoluto de vereadores que formalizaram ao menos uma indicação por legislatura.

Gráfico 1

Número de vereadores que usaram indicações por legislatura

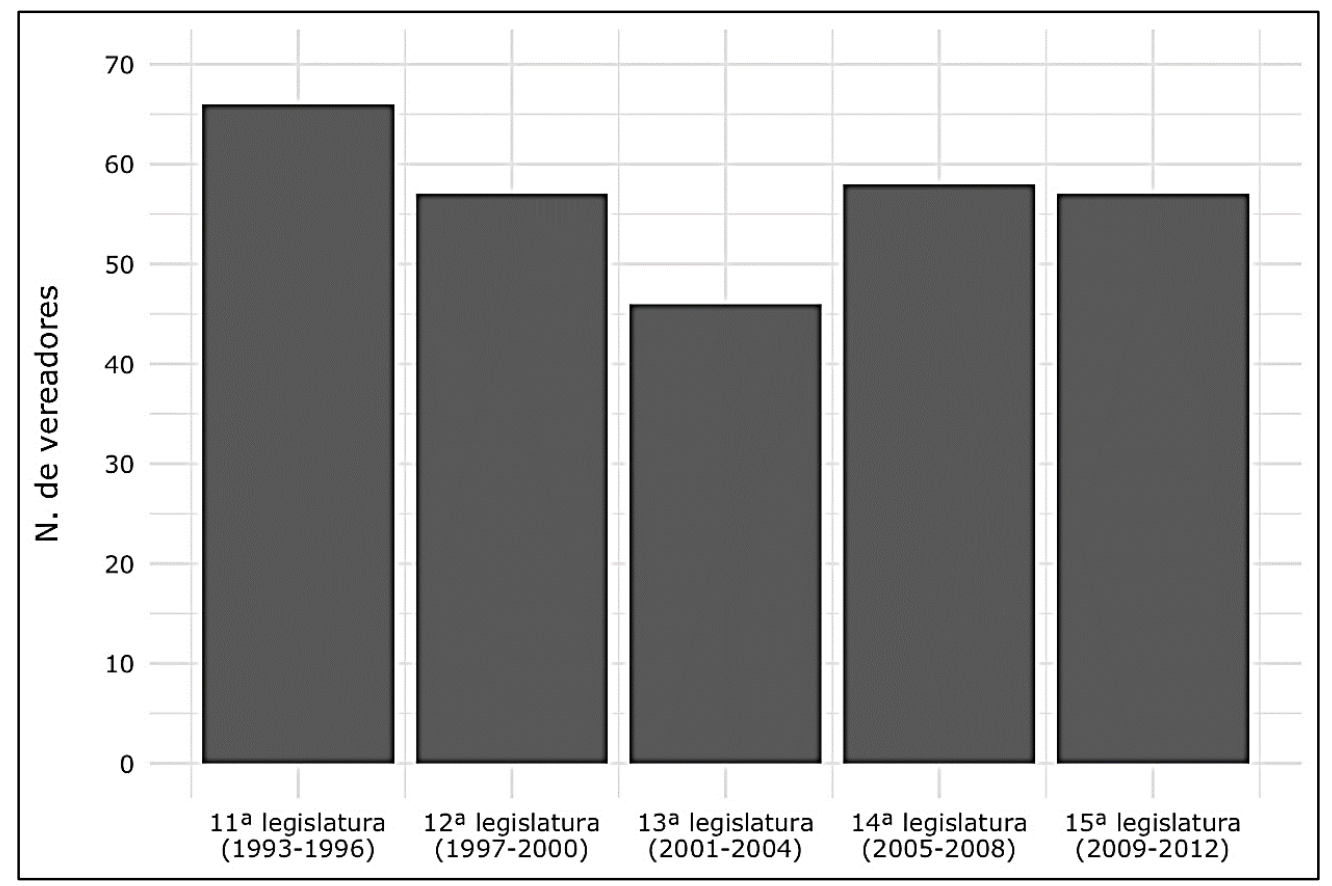

Fonte: Elaborado pelos autores a partir de dados da CMSP.

\section{Quem utiliza}

Para identificarmos padrões de utilização das indicações pelos vereadores, realizamos uma categorização por meio de um algoritmo $k$-means de clusterização (Tan et al., 2019). Essa técnica categoriza as observações de um conjunto de dados em $k$ grupos, sendo $k$ o número de grupos definido pelo pesquisador, por meio da proximidade de um dos $k$-centroides estabelecidos. Dessa forma, as observações mais próximas entre si são atribuídas ao mesmo grupo. Para estabelecermos o número de grupos, utilizamos a função 
NbClust $^{12}$ (do pacote de mesmo nome no R), encontrando que o melhor número de clusters é três, para o número de indicações por ano ou por legislatura. Sendo assim, agrupamos as observações em três diferentes grupos.

Attila Russomanno, um dos vereadores (que será abordado mais detidamente na próxima subseção), é um forte outlier em relação aos demais. Nas duas legislaturas em que ele exerceu mandato, foi responsável por quase $60 \%$ do total das indicações formalizadas. Sendo assim, para nossa análise, também retiramos os outliers do agrupamento ${ }^{13}$, visto que as duas observações referentes a esse vereador compunham um dos três grupos. Com a retirada dos outliers, ganhamos um pouco mais de nuance entre os grupos.

\section{Gráfico 2}

Percentual do total de indicações por vereador, agrupados de acordo com esse valor

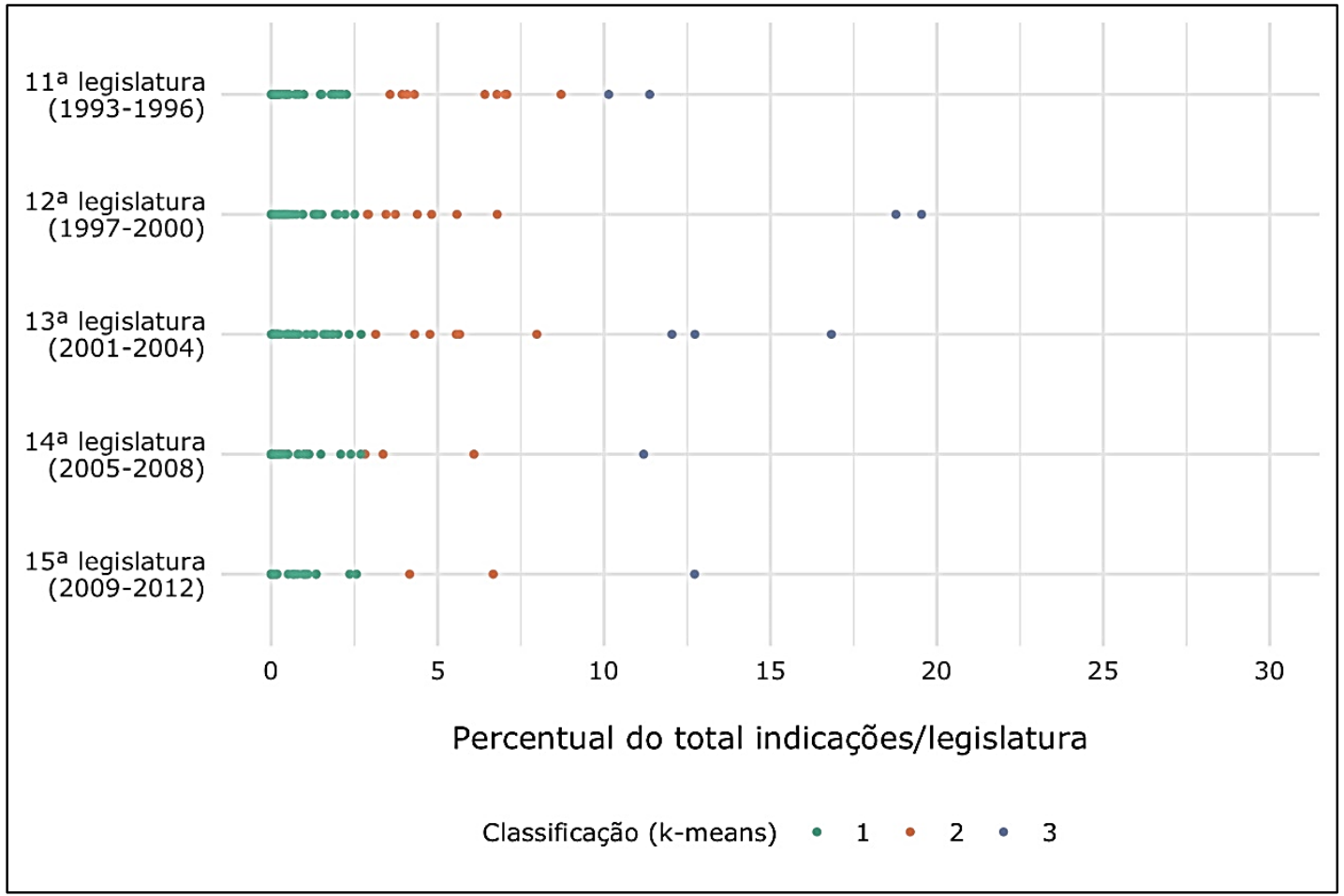

Fonte: Elaborado pelos autores a partir de dados da CMSP.

\footnotetext{
12 Essa função recorre a 30 índices identificados na literatura para indicar qual o melhor número de clusters para o conjunto de dados em análise (Charrad et al., 2014).

13 Utilizamos novamente a função NbClust do R para estimar o melhor número de clusters para esse novo conjunto de dados (sem os outliers). Mais uma vez obtivemos o número de 3 . Sendo assim, as demais observações foram categorizadas em três grupos.
} 
Podemos ver no Gráfico 2 que a maior parte dos vereadores emite poucas indicações em relação ao total e estão classificados no primeiro grupo, constituído somente por vereadores que emitiram até $2,7 \%$ do total de indicações de cada legislatura. 0 segundo grupo é composto por vereadores que foram responsáveis por entre $2,8 \%$ e $8,71 \%$ das indicações, enquanto o terceiro é aquele com menor número de vereadores somente aqueles que têm entre 10,14\% e 19,54\% das indicações. Esses grupos nos permitem verificar que o volume de indicações feito pelos vereadores varia, mas que a maior parte deles faz poucas indicações em relação ao total.

\section{Como indicações se distribuem no espaço}

O padrão geral encontrado é que, no agregado, as indicações de um mesmo vereador estão dispersas pela cidade ${ }^{14}$. Considerando as indicações por legislatura, a distância média das indicações ${ }^{15}$ emitidas por um mesmo vereador é de $13 \mathrm{~km}$, sendo que poucos são os vereadores com distâncias médias pequenas entre suas indicações ${ }^{16}$. 0 Gráfico 3 ilustra esse resultado, considerando os grupos descritos na subseção "Quem utiliza". Vemos que poucos são os vereadores com distâncias médias pequenas entre suas indicações. O gráfico inclui a informação com a retirada dos outliers e a classificação nos três grupos. O primeiro grupo ocupa toda a distribuição (média de $12,77 \mathrm{~km}$ ), ao passo que o segundo (média $=14,18 \mathrm{~km}$ ) e o terceiro (média $=13 \mathrm{~km}$ ) grupos se concentram ao redor da média (os dois "buracos" no histograma correspondem às observações referentes ao vereador Attila Russomanno - média $=17,58 \mathrm{~km}$ ).

\footnotetext{
14 Nesta subseção, fazemos uso das mais de 75 mil indicações georreferenciadas nas cinco legislaturas em análise para identificar como elas se distribuem no espaço e quais padrões conseguimos encontrar nessa distribuição.

15 Para criar esse indicador, calculamos a distância entre cada um dos pontos que representavam as indicações e, em seguida, tiramos a média desse conjunto de distâncias. Foram excluídos aqueles que emitiram apenas uma indicação

16 Foram excluídos vereadores que formalizaram apenas uma indicação que tenha sido geocodificada. 0 desvio-padrão dessa distribuição foi de $4,67 \mathrm{~km}$.
} 


\section{Gráfico 3}

Distância média entre as indicações de um vereador por grupo ( $k$-means)

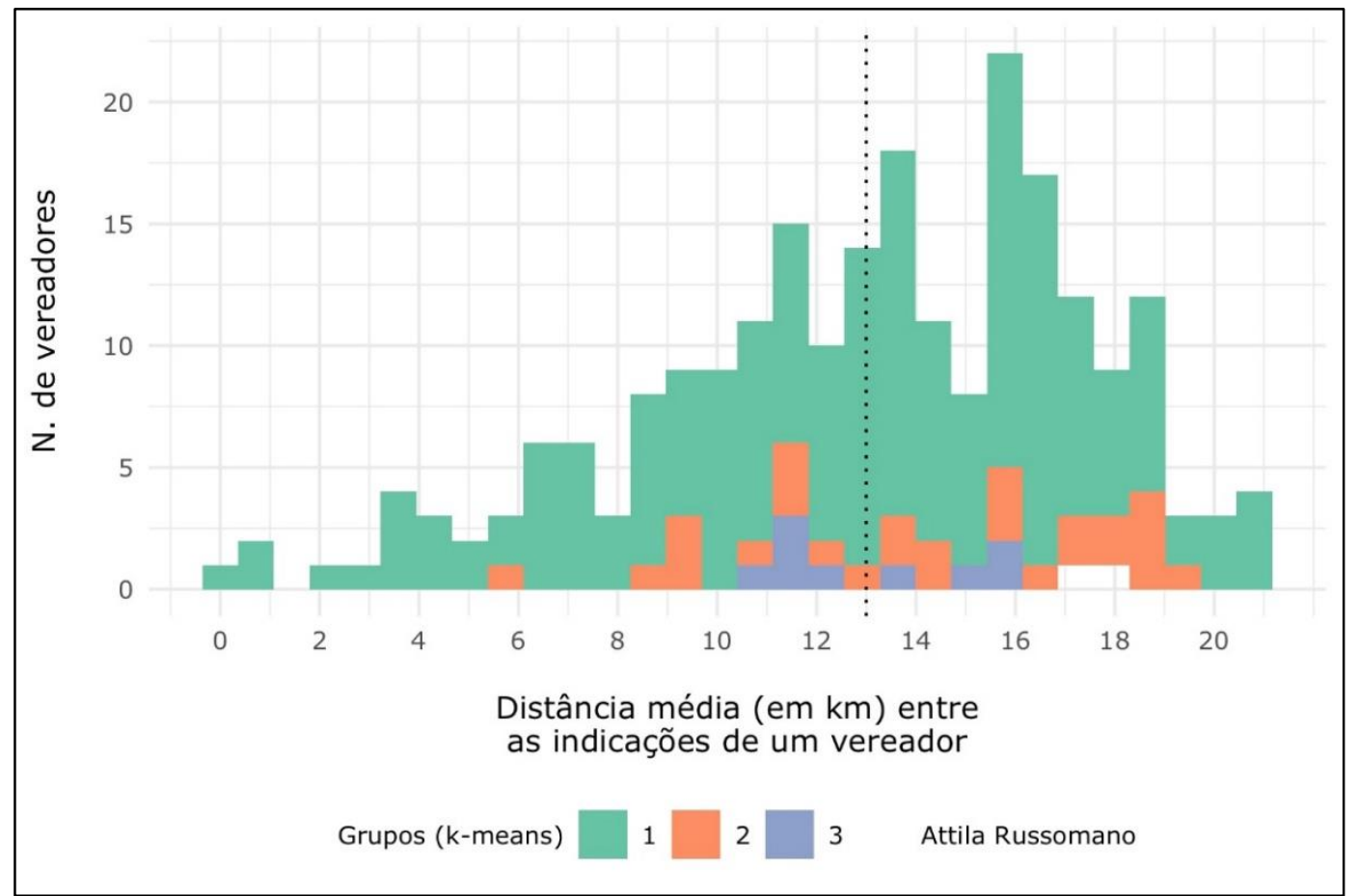

Fonte: Elaborado pelos autores a partir de dados da CMSP.

Das distâncias médias elevadas, contudo, não se pode derivar que não haja trabalho territorial ou mesmo concentração na atuação desses parlamentares. Essas distâncias médias somente nos permitem refutar a hipótese de que a estratégia predominante seja concentrá-las majoritariamente em uma única região (ou poucas regiões próximas entre si $)^{17}$.

Os dois mapas abaixo (Figura 1) evidenciam esse fenômeno. Selecionamos as indicações de dois vereadores (cada um em uma legislatura), Dalton Silvano (13a legislatura) e Gilson Barreto $\left(11^{a}\right)$, com distâncias médias entre indicações próximas a 13 km (média do nosso conjunto de dados). Apesar dessa distância média, vemos com clareza a existência de clusters de indicações. Embora tenham emitido indicações espalhadas pela cidade, Dalton Silvano registra uma presença forte na região de fronteira entre os distritos de Vila Mariana, Liberdade, Cambuci e Ipiranga, além do distrito de Cidade Tiradentes, ao passo que as indicações de Gilson Barreto se destacam nos distritos de São Mateus e São Rafael, na Zona Leste.

\footnotetext{
17 Isso também está em consonância com estudos sobre a concentração do voto em eleições proporcionais no Brasil. Se tomarmos os votos como evidências de ligações dos políticos com regiões, a votação de candidatos eleitos, seja para vereador (Kinzo, Borin e Martins Jr., 2003; Gelape, 2017), deputado estadual (Corrêa, 2016) ou deputado federal (Avelino, Biderman e Silva, 2016), é predominantemente dispersa.
} 
Figura 1

Indicações georreferenciadas dos vereadores Dalton Silvano (13 ${ }^{a}$ legislatura) e Gilson Barreto (11 ${ }^{\text {a }}$ legislatura)

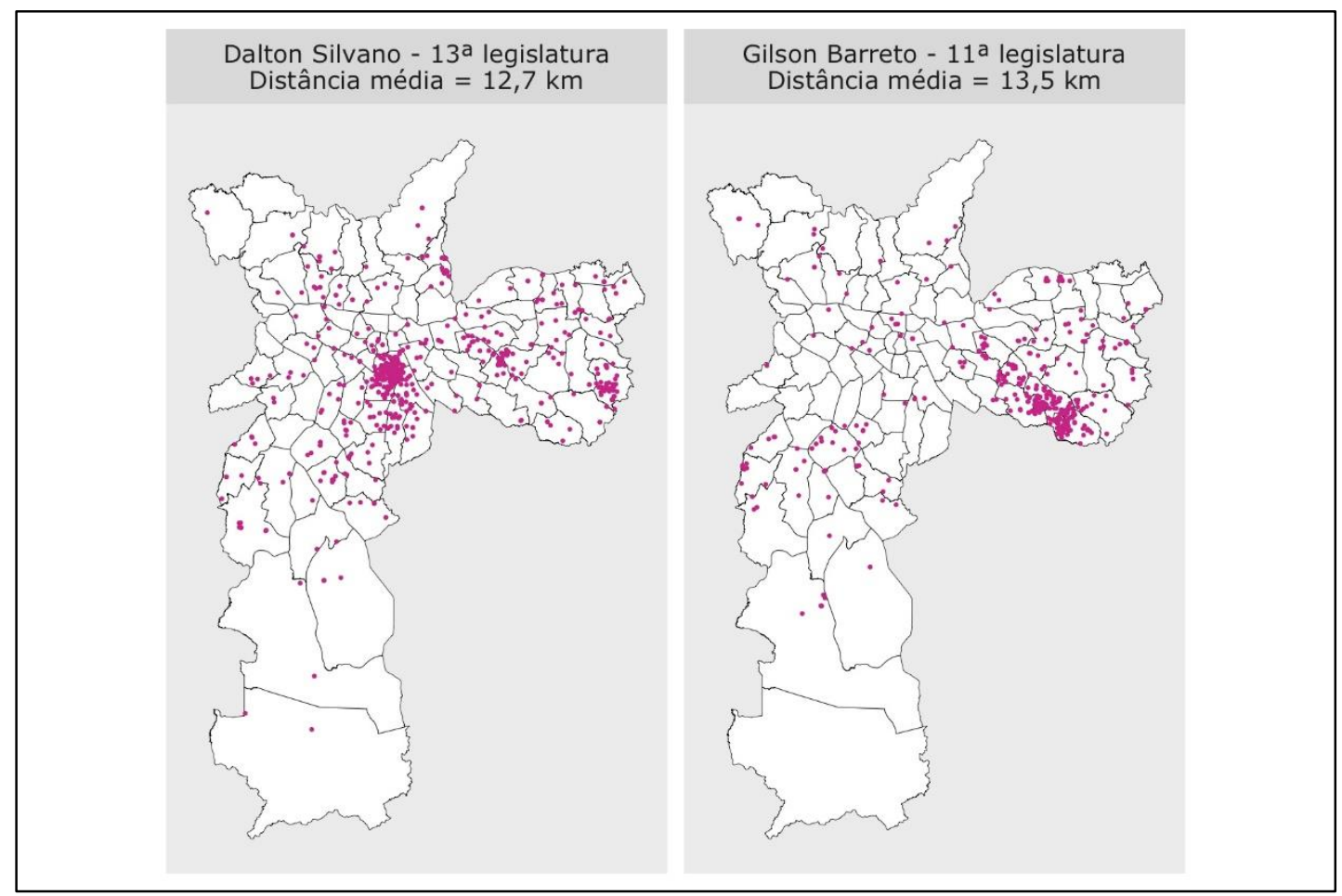

Fonte: Elaborado pelos autores a partir de dados da CMSP e do IBGE.

Quão generalizável é esse padrão entre os vereadores analisados? Ou seja, também encontramos clusters de indicações para os demais vereadores? Arbia, Espa e Giuliani (2015, seção 3) explicam que indicadores de autocorrelação espacial global (como o I de Moran) não são apropriados para testar concentração espacial em dados de área. Portanto, para identificarmos a existência de áreas com expressivo volume de indicações, utilizamos testes de autocorrelação espacial local (Lisa, em sua sigla em inglês) para identificar esses clusters. Segundo Anselin (1995, p. 94, tradução nossa), um dos elementos definidores do Lisa é que "(...) para cada observação ele indica a extensão de uma clusterização espacial significante de valores semelhantes ao redor de uma observação".

Assim, utilizaremos o Moran Local como indicador da existência de clusters de observações que tenham um volume alto e estatisticamente significante de indicações numa área em relação aos vizinhos ${ }^{18}$. Estimamos a autocorrelação espacial local para todos

\footnotetext{
18 O Moran Local foi calculado a partir do pacote spdep, do R (Bivand, Pebesma e Gómez-Rubio, 2013; Bivand e Wong, 2018). Os mapas com os resultados da categorização do Moran Local estão disponibilizados no site do Cesop: <cesop.unicamp.br>, na página deste artigo (seção Revista Opinião Pública).
} 
os vereadores que tenham protocolado ao menos 30 indicações que conseguimos georreferenciar ao longo de uma legislatura, que resultam em 135 pares de vereadorlegislatura $(53,1 \% \text { dos pares no banco de dados })^{19}$. Agregamos as indicações realizadas por vereadores em duas unidades geográficas ${ }^{20}$ (distritos e subprefeituras) e definimos a matriz de vizinhança com base em uma matriz de contiguidade queen de primeira ordem.

No Moran Local, testamos a hipótese nula $\left(\mathrm{H}_{0}\right)$ de inexistência de autocorrelação espacial, e a interpretação de seus valores é semelhante à do indicador global, porém levando em conta somente essa observação e seus vizinhos definidos pela matriz de vizinhança. Com base nos resultados da estatística-teste, classificamos cada observação (unidade geográfica de um vereador-legislatura) em uma de cinco categorias: alto-alto, alto-baixo, baixo-baixo, baixo-alto e sem significância estatística. Cada categoria indica a relação do valor da variável de interesse na observação (o número de indicações por unidade geográfica) com o de seus vizinhos, condicionada pela significância estatística do teste. Se a unidade não é classificada como sem significância estatística, ela atingiu valores menores do que o p-valor máximo estabelecido para o teste (em geral, 0,05 para um nível de confiança de $95 \%$ ) e identifica essa relação. Por exemplo, áreas identificadas como altoalto apontam que uma observação possui valores altos da variável de interesse, tal como seus vizinhos.

Nesse sentido, nossa hipótese é que a existência de clusters alto-alto ou alto-baixo aponta para uma estratégia de concentração na atuação dos vereadores e seus brokers em certas regiões da cidade. Isso porque a existência de observações com um valor alto de indicações sugere um esforço do vereador naquela região. A inexistência de tais clusters seria evidência contrária a uma atuação territorial desses políticos.

Com base na agregação das indicações em distritos e em um nível de confiança de $95 \%$, todos os vereadores-legislatura analisados (aqueles com mais de 30 indicações protocoladas e georreferenciadas por legislatura) apresentaram unidades geográficas classificadas como alto-alto ou alto-baixo. Ao adotarmos um nível de confiança mais exigente (99\%), somente dois dos vereadores não apresentam esses clusters $(1,5 \%$ do total em análise). Esses dados fornecem evidências sugestivas de trabalho territorial dos vereadores em certos distritos paulistanos. A título de exemplo, reproduzimos os mapas com os Lisa de Dalton Silvano (13 ${ }^{\text {a }}$ legislatura) e Gilson Barreto (11 ${ }^{\text {a }}$ legislatura) exibidos anteriormente, nos quais os clusters alto-alto coincidem com as regiões em que apontamos a predominância de indicações.

\footnotetext{
19 Os resultados são robustos diante do aumento ou da diminuição desse número. Realizamos os mesmos testes considerando um mínimo de 20 ou 40 indicações por legislatura. No primeiro caso, aumentamos o número de pares considerados $(60,6 \%$ do total) e, no segundo, diminuímos ( $50 \%$ do total). Em ambos, os resultados vão no mesmo sentido daqueles reportados no restante da subseção.

20 Buscando investigar a incidência do MAUP (modifiable areal unity problem), no qual escalas diferentes podem condicionar as inferências realizadas (Darmofal, 2015, p. 26-27; Gonçalves, 2016).
} 
Figura 2

Lisa (Moran Local) do número de indicações por distrito Vereadores Dalton Silvano (13 ${ }^{a}$ legislatura) e Gilson Barreto (11 ${ }^{\text {a }}$ legislatura)

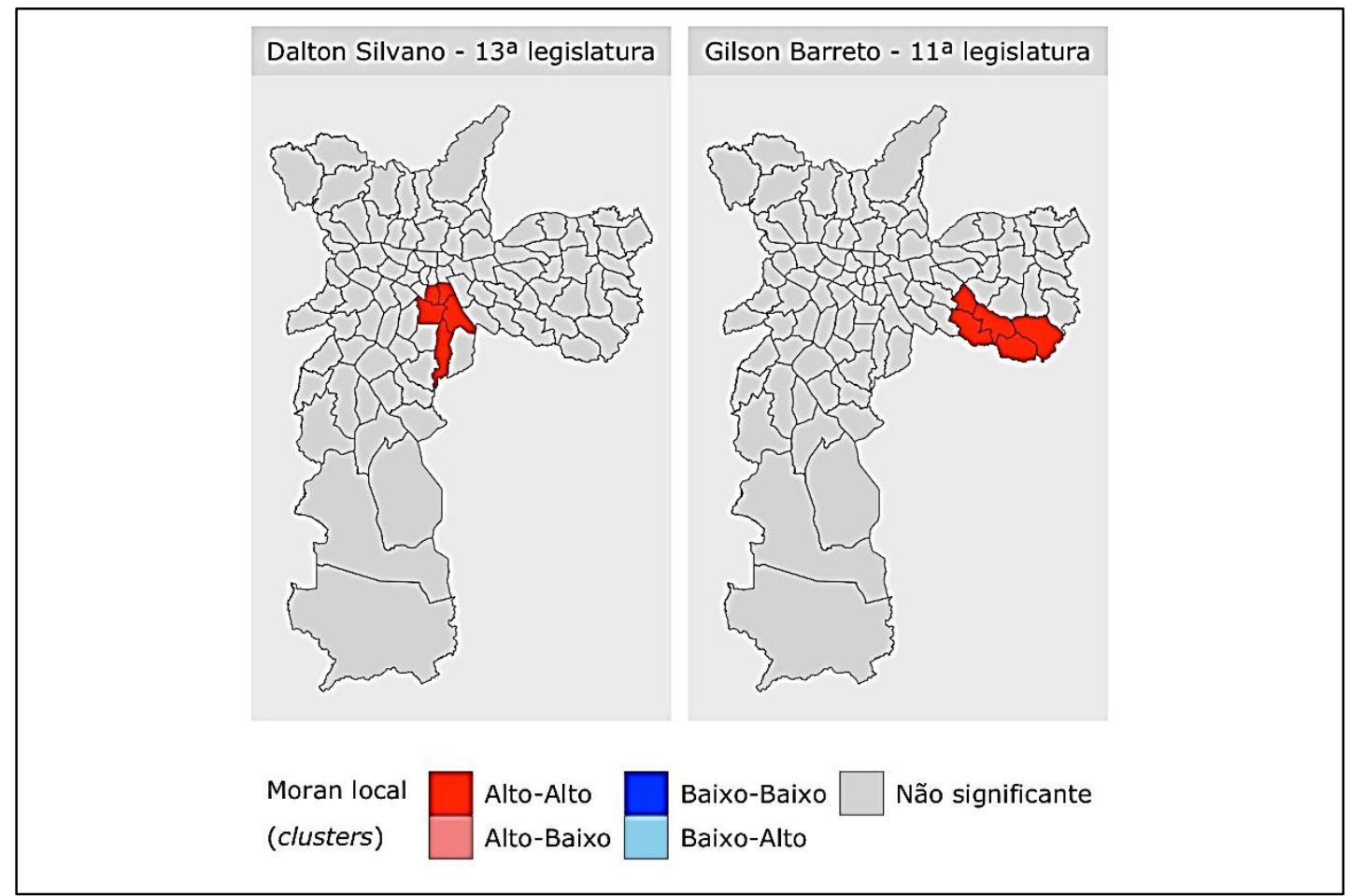

Fonte: Elaborado pelos autores a partir de dados da CMSP e do IBGE.

Se as indicações forem agregadas em subprefeituras, essa relação é menos evidente, mas ainda é verificada. Cerca de $85,9 \%$ dos pares vereador-legislatura (sob um nível de confiança de $95 \%$ ) com mais de 30 indicações apresentaram áreas classificadas como alto-alto ou alto-baixo - ou $77,8 \%$ sob um nível de confiança de $99 \%$. Dessa forma, acreditamos que os Lisa acrescentam evidências quanto à realização de construção de vínculos territoriais dos vereadores por meio das indicações.

Subprefeituras são órgãos importantes do funcionamento da política paulistana (Grin, 2015) e centrais na execução de serviços de zeladoria, área de destaque entre indicações. Para o gerenciamento da coalizão, o Executivo concede aos vereadores forte influência na nomeação de seus cargos. Os vereadores, por sua vez, procuram cargos naquelas subprefeituras que concentram o maior número de distritos em que atuam, mas isso não significa que estes têm controle absoluto sobre os cargos ou o território da subprefeitura. Isso nos ajuda a entender o resultado acima, que pode, alternativamente, 
ser lido como a constatação de que os vereadores emitem parte considerável de suas indicações dentro de uma (ou poucas) subprefeituras ${ }^{21}$.

Isso sugere que, embora politicamente relevantes, as subprefeituras não são a melhor unidade de agregação para identificar a atuação de brokers no espaço, pois elas circunscreveriam parte considerável das indicações de um mesmo vereador, porém com pouco spillover entre regiões vizinhas, afetando essa relação de vizinhança, ao contrário do que seria observado entre distritos dentro de uma subprefeitura. Dessa forma, obteríamos uma série de falsos negativos, pois os vereadores teriam atuação territorial, mas os resultados dos testes não permitiriam que rejeitássemos $\mathrm{H}_{0}$ (erro do tipo II).

Em resumo, nossos resultados sugerem que vereadores concentram indicações em algumas áreas da cidade de São Paulo, uma vez que identificamos clusters de áreas com alta incidência de indicações protocoladas por um vereador ao longo de uma legislatura. Além disso, os distritos - na ausência de uma unidade oficial de agregação espacial mais granulada como os bairros - parecem uma unidade geográfica mais adequada para observarmos a clusterização de indicações, se comparados às subprefeituras. Mesmo que entre as duas divisões administrativas oficiais os distritos apareçam como unidades de agregação significativas, o trabalho qualitativo sugere que as indicações não acontecem em distritos, mas sim em regiões menores, pelos vínculos criados pelos brokers. O padrão de distribuição espacial das indicações não constitui uma estratégia isolada, relacionandose com a dinâmica mais ampla do mandato parlamentar.

Vereadores paulistanos contam com um gabinete composto formalmente por um chefe de gabinete e até 17 assessores parlamentares. Via de regra ${ }^{22}$, apenas dois ou três desses assessores (de imprensa, jurídicos, legislativos ou relacionados a outras funções específicas conforme a organização do mandato) permanecem de fato ocupando o espaço do gabinete para trabalho cotidiano. Todos os demais realizam trabalhos territoriais. Assim, embora assessor parlamentar seja o nome formal para ocupantes de um gabinete parlamentar, utilizamos neste artigo a nomenclatura broker para designar a função desempenhada pela maior parte dos assessores, justamente pela natureza do trabalho que executam nos territórios, a de intermediação política.

A trajetória de vida dos brokers e as relações que eles têm com outros assessores, tal como nos foi relatado por meio das entrevistas, apontam que existe rotatividade dos brokers ao longo de todo o período que um vereador permanece na Câmara. Essa rotatividade pode ser provocada pela disputa por cargos e recursos, por intrigas internas, pela oferta de melhor remuneração por outros vereadores, pela estratégia de expansão de vínculos nos territórios e pelo resultado de eleições em outros níveis federativos que

\footnotetext{
${ }^{21}$ Isso fica mais claro na observação dos mapas em que plotamos as indicações como pontos, como na Figura 1.

22 Há vereadores, como Fernando Holiday, que centram atenção na construção e promoção de sua imagem em redes sociais de maneira bastante importante, considerando como distribui competências entre seus assessores. No mais das vezes, a divulgação em redes sociais é combinada com o trabalho territorial.
} 
empregam ou desempregam pessoas de grupos políticos próximos. Ao saírem de um mandato, brokers podem levar para outros políticos territórios em que possuem vínculos e podem também deixar um espaço vazio a ser ocupado, como também sugeriu Novaes (2018) em suas explicações sobre "brokers desleais". Analogamente, brokers podem também trazer novos territórios ao se associarem a um mandato, ampliando a área de influência do vereador. Como as indicações são um dos instrumentos de criação desses vínculos, a fotografia de sua distribuição espacial em determinado momento capta também os territórios em que o vereador acaba de criar ou perder vínculos em função dessa dinâmica. Isso justificaria pontos isolados, que aparecem espacialmente distantes.

A disputa política permanece entre os brokers que querem expandir sua área de influência. Veremos na subseção seguinte um exemplo empírico de como isso se expressa no momento de fazer uma indicação.

\section{Como nascem as indicações}

Indicações são um instrumento útil para construção de vínculos. Elas permitem a captação e a resolução de problemas pelos quais é possível fazer credit claiming, mas também evidenciam a atuação diária junto à população de determinado bairro ${ }^{23}$. Quando começam a trabalhar para um vereador ou dão início a sua inserção em um novo território, brokers realizam uma busca ativa por demandas no contato direto com a população. "Se precisar de alguma coisa, pode contar comigo"24 - é como eles procuram deixar claro aos seus vizinhos, ao dono da padaria, do bar, que aqui enquadraremos como "moradores". Ao identificar um problema, procuram alguém que possa notar sua resolução, misturando credit claiming e a preocupação com o uso do serviço: "A gente não tem que querer nada, as pessoas têm que dizer o que querem, senão depois ninguém sabe que a gente fez e a praça fica lá, sem uso"25. Mas, à medida que se tornam conhecidos, a busca ativa diminui e são os moradores desses bairros que levam a eles suas demandas.

Um caso típico (no sentido de que diversas histórias são narradas por brokers de diferentes partidos com fluxo e procedimentos similares) de como nascem indicações é descrito pelo broker Antônio:

(...) a gente está construindo um trabalho com o pessoal lá da Vila Nova já faz um tempo já, daí um vai falando pro outro (...) e chegou um pedido de ajuda pra gente falar com a CET [Companhia de Engenharia de Tráfego]. A rua Caique Reis tem uma curva bem fechada e depois que ela foi recapeada os carros passaram a circular com uma velocidade bem alta. Então o pessoal da rua estava pedindo a implantação de redutores de velocidade, em especial

\footnotetext{
${ }^{23}$ A Figura $1 \mathrm{~A}$ do Apêndice mostra o exemplo de texto de um ofício de indicação ao Executivo e a folha de solicitação pela qual a demanda é coletada junto à população.

24 Entrevistado: Bruno (partido do governo) - entrevista concedida em setembro de 2018.

25 Conversa com Antônio (broker do vereador Paulo) em outubro de 2018.
} 
perto do número 209, onde fica a curva. A gente protocolou o pedido, a CET foi lá, fez um estudo e implantaram dois redutores de velocidade. Daí é isso... a gente às vezes coloca faixa [do vereador], às vezes nem precisa, no dia a dia a gente vai falando pras pessoas que a gente conseguiu e que foi uma conquista deles também, né? Esse caso eu divulguei no Facebook.

Brokers também operam filtrando demandas e aumentando o custo político para vereadores concorrentes em um mesmo território. O trecho abaixo, obtido quando andávamos de carro pela região em que Júlio ${ }^{26}$ atua, ilustra como tanto o broker pode adotar a estratégia de aumento do custo político para a oposição que controla a subprefeitura, como a própria subprefeitura, órgão fundamental para canalizar e resolver demandas de zeladoria urbana, também faz um filtro ao credit claiming de um vereador concorrente no território:

Olha o tamanho dessa cratera. Cai um carro nisso aí, não sai mais. Eu até podia tentar resolver, mas não vou. Tô cansado! Você protocola o pedido na subprefeitura e se ela tiver com a concorrência, nem te atendem. Tem lugar que é mais tranquilo, aqui nem olham na sua cara. Então o que eu tô fazendo é mostrar pro povo aqui do bairro como a cidade está abandonada com essa administração. Toda vez que eu passo aqui, eu comento isso. Eles vêm me pedir pra resolver e eu falo que o vereador [concorrente na região, que ocupa os cargos da subprefeitura] e o prefeito não deixam.

Artur ${ }^{27}$ relatou uma experiência diferente da de Júlio. Enquanto Júlio é broker em uma região bastante pobre na cidade, Artur concentra sua atuação em um bairro de classe média e relata seu processo de formular indicações como uma intermediação de protocolos feitos pelos próprios cidadãos - algo que não é tão simples de pedir a munícipes de baixa renda, que muitas vezes não possuem acesso a interfaces digitais ou familiaridade com elas e conhecem menos seus direitos. Além disso, como atua para um vereador que não faz oposição declarada ao governo, ele consegue contornar com mais facilidade eventuais disputas partidárias, que Júlio não consegue. Segundo ele,

O trâmite é assim: aqui todo mundo já me conhece, então tudo vem pra mim. É sinalização de CET, poda de árvore, paisagismo de praça... Como é um bairro de classe média, média alta, é mais essas coisas... O que eu faço, que eu vi que dá certo, é pedir pra própria pessoa ligar no 156 e me passar o número do SAC. Daí eu peço pro gabinete fazer um ofício, eles mandam o original pra subprefeitura e me mandam uma foto que eu já encaminho pra um amigo meu lá dentro "ô, fulano, pode agilizar isso pra mim?".

\footnotetext{
${ }^{26}$ Broker do vereador Pereira (posição de "independência" em relação ao governo Bruno Covas) - observação participante realizada em setembro de 2018.

27 Broker do vereador Paulo - entrevista concedida em março de 2019.
} 
Quando perguntamos se isso depende de o subprefeito e o vereador serem oposição ou não, Artur respondeu: "Isso influencia porque podem ir empurrando, mas se tem bom relacionamento com o pessoal interno, de carreira, se tem articulação lá dentro [da subprefeitura] consegue".

Esse trecho, além de evidenciar como o alinhamento ao governo da prefeitura influencia a resolução do problema, mostra também que as demandas existem na classe média e que a função que o broker precisa desempenhar se altera. Em bairros mais pobres, além de encaminhar o ofício, é o próprio broker quem faz o protocolo oficial do pedido (no canal 156), ao passo que, nos de classe média, o broker pode apenas se ocupar de "agilizar" a tramitação (de pedidos que, nesse caso, são feitos geralmente pelos moradores). As demandas e a frequência dos pedidos se alteram em bairros pobres, médios ou ricos em função da distribuição desigual de políticas que se sobrepõem no espaço e formam padrões de desigualdade na cidade (Marques, 2015); porém, independentemente disso, essa diferença (a variação relacionada ao status socioeconômico do bairro) aproxima cidadãos em termos da relação que têm com brokers. A literatura sobre clientelismo enfoca apenas o contato de brokers com a população mais pobre, embutindo na explicação pressupostos elitistas.

Como mencionamos, nem todas as atividades de intermediação que um broker realiza são objeto de formalização na base de dados, e muitas são "encaminhadas" a colegas na burocracia do Executivo na base do "diálogo". Por vezes, o próprio broker acompanha as pessoas na resolução de seus problemas cotidianos, dispensando o uso de documentos. Parte da tarefa de um broker é saber quando recorrer a cada uma dessas estratégias.

Tanto a observação participante quanto as entrevistas identificaram que, na maior parte dos casos, o vereador sequer toma conhecimento do conteúdo das indicações. Em uma cidade como São Paulo, que se destaca pelo tamanho do seu eleitorado, pela sua importância no cenário político nacional e pela complexidade na produção de políticas urbanas, o vereador concentra sua atuação na articulação política mais ampla. São os brokers que procuram fazer o atendimento das indicações no cotidiano do mandato. Alguns brokers como Artur, inclusive, identificam o efeito positivo que isso tem sobre a solução do problema, uma vez que podem driblar a questão partidária por meio de vínculos com burocratas de médio escalão que são formados a partir de convívios prévios em um mesmo espaço, como numa secretaria municipal ou num mandato parlamentar, o que seria mais difícil quando a negociação é feita pelo vereador no alto escalão. Apenas as indicações de grande importância e difícil solução são comunicadas pelos brokers aos vereadores.

A indicação é um instrumento que ajuda os brokers a construírem vínculos com os moradores de determinada região, mas o sucesso dessa empreitada não é garantido, uma vez que a construção de vínculos não é apenas uma questão técnica e estratégica, mas também de ordem pessoal, como a literatura já demonstrou (Ayuero, 1999, 2000). O sucesso na criação de vínculos está relacionado não apenas ao instrumento, mas à forma 
como o mandato e os brokers utilizam os instrumentos à sua disposição, como evidencia o caso do vereador Attila Russomanno.

Russomanno é um outlier importante em nossa análise, uma vez que ele é responsável por parte considerável das indicações da nossa base de dados (mais de 26.000 delas, o que corresponde a quase $30 \%$ do total, considerando todas as legislaturas) e também reforça a explicação da importância da criação de vínculos. Attila foi eleito em 2004 com a força de seu sobrenome, pelo qual os eleitores o associavam ao seu irmão Celso Russomanno 28 , bastante conhecido pela sua presença na televisão. Assim, Attila foi eleito com mais de 25 mil votos, distribuídos de forma bastante pulverizada na cidade.

Em cada uma das duas legislaturas em que exerceu mandato, ele foi responsável por quase $60 \%$ das indicações formalizadas (totalizando 14.222 entre 2005 e 2008, e outras 12.135 em 2011 e 2012). A distância média entre as suas indicações é ainda mais alta do que a média geral: 17,58 km. Além disso, ele possui uma distribuição espacial de indicações que progressivamente foi se espraiando por toda a cidade, como mostram os mapas abaixo.

\section{Figura 3}

Indicações georreferenciadas do vereador Attila Russomanno (ano)

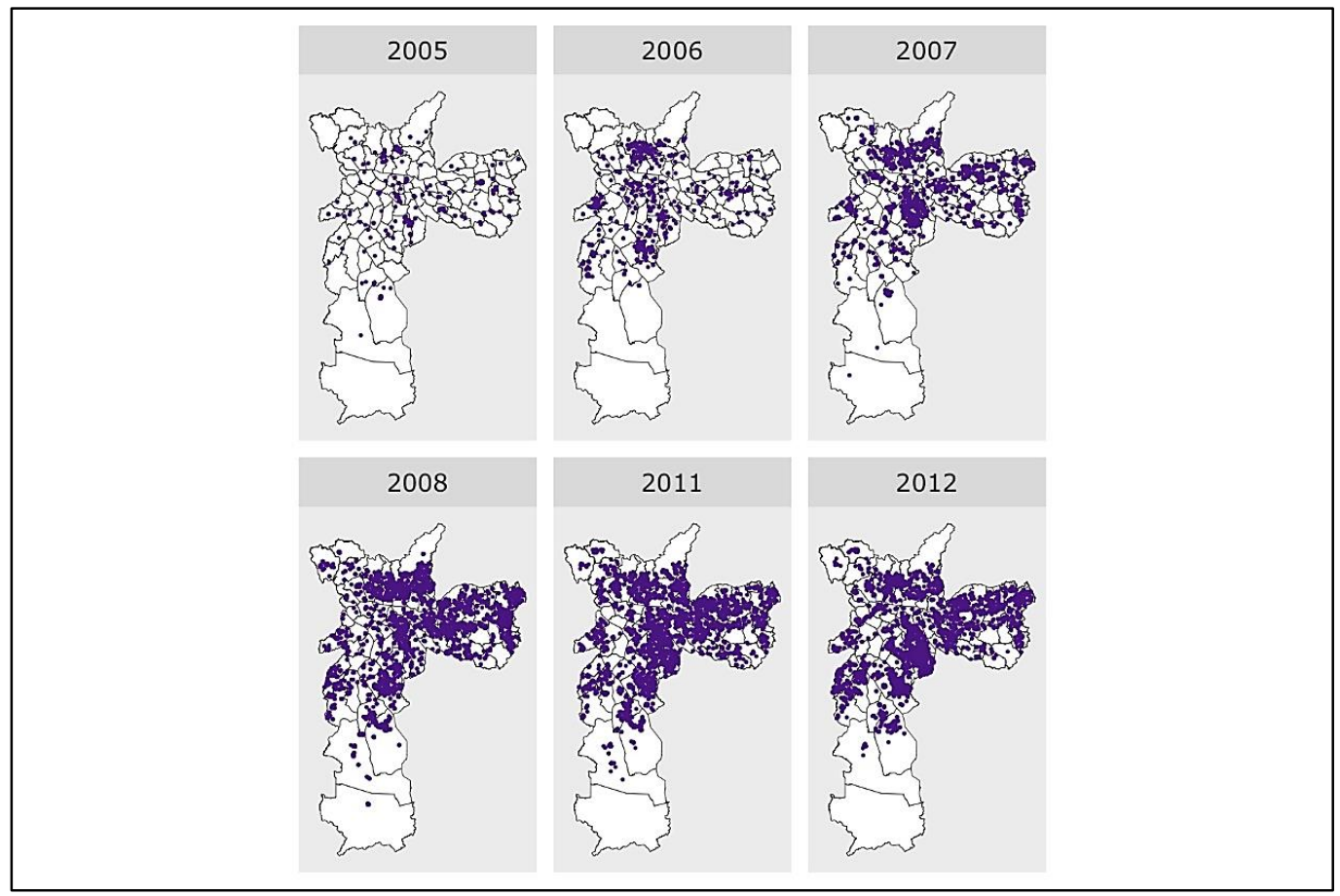

Fonte: Elaborado pelos autores a partir de dados da CMSP e do IBGE.

Nota: Attila Russomanno não foi eleito em 2008, assumindo o mandato como suplente em 2011.

${ }^{28}$ Ex-candidato a prefeito da cidade de São Paulo e deputado federal. Foi uma figura constante em meios de comunicação, como rádio e TV, na atuação de casos sobre direito do consumidor. 
Ao longo de seus mandatos, em vez de concentrar sua atuação, Attila Russomanno adotou uma "estratégia arriscada", como consideraram entrevistados que conviveram com o vereador na Câmara. Essa estratégia consistia em enviar brokers para eventos abertos e locais com grande fluxo de pessoas (como feiras de rua e pontos de metrô) espalhados por toda a cidade, de maneira a captar demandas relacionadas a problemas dos bairros e convertê-las em indicações. Como os brokers operavam em locais onde não necessariamente tinham vínculos, além de eles não estabelecerem aí um trabalho político suficientemente duradouro e substantivo para construí-los, a população dessas regiões raramente recebia um retorno sobre suas solicitações.

Além disso, diante do volume de indicações, o acompanhamento da solução do problema dificilmente ocorria. Ao chegarem à CMSP, vindos das ruas, os brokers de Attilla Russomanno protocolavam as indicações na burocracia (possivelmente esse é um dos únicos casos em que todas as indicações feitas pelo vereador constam na base de dados) e consideravam o trabalho finalizado. Ou seja, embora numerosas, as indicações tornavam-se inefetivas do ponto de vista eleitoral e das políticas públicas, pois não tinham sua tramitação monitorada (e acelerada) no Executivo. E como não criavam vínculos, os brokers raramente ofereciam um retorno à população sobre os motivos de uma eventual demora ou impossibilidade de resolução do problema. Attila Russomanno empreendeu essa estratégia de maneira progressiva e crescente, tendo mantido um alto volume de indicações até 2012, quando, com apenas 6.741 votos, não foi reeleito.

\section{Acompanhamento da tramitação e comunicação com a população}

Uma vez enviadas aos órgãos do Executivo, as indicações integrarão o conjunto de demandas que o órgão recebe, sendo preciso realizar o monitoramento constante da solicitação. "A gente oficializa, mas tem que ficar em cima, senão não sai. Muita coisa eu consigo porque conheço gente lá dentro", como Antônio disse a um colega do mesmo mandato ${ }^{29}$.

A operacionalização desse acompanhamento junto aos órgãos do Executivo depende de como cada mandato organiza suas rotinas e processos internos. Alguns gabinetes possuem um assessor de perfil administrativo, responsável pela gestão de um banco de dados interno, que registra todas as indicações feitas, data e órgão para o qual foi encaminhada, endereço ao qual se destina, status de atendimento e nome do broker responsável por trazer a indicação ao gabinete. Essa gestão também pode ser feita de maneira individual por cada broker. Em um dos sistemas internos (ao gabinete) que vimos, a planilha que listava os ofícios tinha ainda um campo "carta", em que o assessor registrava se já havia sido feito o envio de uma carta aos moradores do bairro onde a indicação foi

\footnotetext{
29 Observação participante - fevereiro de 2019.
} 
solicitada para informar, em caso de cumprimento, que isso ocorreu pelo protagonismo do vereador em questão e, em caso de não atendimento, as razões para isso, num exemplo evidente de como esse instrumento pode ser utilizado para credit claiming. Como já é conhecido na literatura (Kuschnir, 2000), um cadastro dos moradores dos bairros ao qual o vereador destina suas ações é uma prática bastante comum entre vereadores e uma etapa fundamental para que essa comunicação aconteça durante todo o mandato. Em caso de demora na execução do serviço, a carta também é enviada, mas, nesse caso, contendo o ofício de solicitação ao Executivo em anexo.

Segundo um vereador entrevistado ${ }^{30}$, para garantir que os brokers possam dar uma resposta a qualquer momento para a população, "eles já saem daqui [gabinete do vereador] com uma cópia do ofício [que será enviado posteriormente ao Executivo]". Assim, é possível que o vereador faça o credit claiming pela execução ou tentativa de execução do serviço e evite, assim, a sua responsabilização pela inexecução. Encontramos consonância na literatura a esse respeito. Segundo D'Ávila, Cerqueira Lima e Jorge (2014), os vereadores dedicam parte substantiva de sua produção à elaboração de um dispositivo que não tem força de lei porque a formalização é garantia suficiente do certificado de autoria, fundamental para a construção da reputação do vereador junto à base local.

Mais recentemente, outra estratégia para credit claiming tem sido o uso de grupos no WhatsApp. Desse modo, além da vantagem de cadastrar o celular de eleitores, o broker pode enviar registros fotográficos dos ofícios trocados com o Executivo e de reuniões em que participou com o intuito de solucionar a demanda. Caso não seja possível executar a solicitação, os moradores terão acompanhado em tempo real todas as investidas do broker para atendê-la. É, ao mesmo tempo, uma estratégia arriscada, uma vez que é preciso mostrar-se bastante proativo na resolução do problema, mas também de bastante retorno do ponto de vista da construção do vínculo, afirmam diferentes brokers.

De maneira unânime, os brokers com os quais conversamos consideram que a estratégia mais eficiente para informar o morador/eleitor sobre o andamento da demanda é o boca a boca. Segundo eles, dessa maneira mostra-se a presença física no território, associada pelos moradores a maiores níveis de atenção às suas demandas. A presença física é muito importante para criar a sensação de que o broker/vereador está empenhado. Tanto a presença física do broker no território quanto a presença da população em reuniões na burocracia são importantes, o que, por vezes, além de possibilitar que o vereador ou o broker mostrem que estão trabalhando para resolver o problema, permite que os moradores compreendam a complexidade envolvida na entrega de políticas. Recorremos a outro relato para ilustrar esse ponto. O caso é sobre iluminação pública.

Em algumas ruas da região onde Júlio atua, a Enel ${ }^{31}$ fez o cabeamento para regularizar o fornecimento de energia elétrica nas casas e na rua, mas o Ilume (órgão

\footnotetext{
30 Entrevista concedida em abril de 2019 - vereador de centro-esquerda.

${ }^{31}$ Empresa concessionária de distribuição de energia elétrica com atuação no estado do São Paulo, incluindo sua capital.
} 
municipal da prefeitura) não havia colocado as lâmpadas nos postes. O problema assumiu grande proporção, pois os moradores passaram a ser assaltados nos trechos escuros e reclamavam da cobrança de energia em suas casas, pois não tinham iluminação pública nas ruas. Não havia, entretanto, uma solução rápida para a questão, uma vez que a parceria público-privada sob a coordenação do Ilume, que deveria então instalar ou substituir todas as lâmpadas da cidade por LED, foi paralisada na justiça por suspeita de improbidade administrativa, e o órgão não poderia fazer nenhuma nova instalação até segunda ordem. Por um ofício de indicação, Júlio havia feito a solicitação ao Ilume e, diante da ausência de retorno, agendou uma reunião com técnicos do órgão, em que também compareceu a chefe de gabinete do vereador. O problema continuou, as reclamações dos moradores e os casos de assalto aumentaram e nova reunião foi agendada para tentar solucionar o problema, ou, pelo menos, mostrar aos moradores que o vereador e sua equipe estavam de fato tentando resolvê-lo. Além dos diretores e burocratas do Ilume, do vereador e do broker, dessa vez Júlio levou também cinco moradores da região.

$\mathrm{O}$ vereador começa apresentando a questão de maneira bastante diplomática e buscando validação com os moradores:

Quero agradecer mais uma vez a gentileza de nos atender, a gente está aqui com o pessoal da Vila Mila, também com o Jeremias que é ali da Vila Zaleti (...). A gente sabe que tem a confusão do contrato da PPP, mas a gente queria apelar pra ver se tem alguma solução emergencial, porque assaltam as mulheres de manhã, o pessoal é abordado na rua (...). É um drama e a gente não consegue mais explicar como a gente não consegue este ponto de luz.

O diretor concorda e lamenta:

Então, vereador, estes pedidos já estão aqui dentro, já estão cadastrados, projetados. Mas, em função dessa PPP, o senhor deve ter acompanhado nosso caso pela imprensa e tudo o mais, em dezembro o juiz mandou cancelar. Autorizou apenas casos de manutenção pra não gerar um caos na cidade, enquanto não se tem um novo contrato, uma nova PPP32.

O vereador insiste diplomaticamente e abre a conversa com os moradores:

Eu não tinha ciência dessa questão, agora eu tenho ciência de como funciona mais ou menos, mas o povo lá não entende. A Enel chega, coloca a energia e começa a cobrar, beleza, mas aí, cadê a iluminação pública? Basicamente é uma coisa à parte, mas o povo em si não entende essa parte.

\footnotetext{
32 Ele refere-se à paralisação pelo TJ da parceria público-privada de iluminação no valor de $\mathrm{R} \$ 7$ bilhões em função de suspeita de fraude na contratação. Para informações midiáticas, ver, por exemplo: <https://g1.globo.com/sp/sao-paulo/noticia/2018/12/12/tj-anula-ppp-da-iluminacao-publica-em-saopaulo.ghtml>; <https://sao-paulo.estadao.com.br/noticias/geral,mais-uma-vez-justica-suspende-ppp-dailuminacao-de-sp,10000082137>. Acesso em: 5 jan. 2020.
} 
A reunião foi encerrada com o compromisso de que técnicos do Ilume agendariam com Júlio uma visita à região e intermediariam a relação com a Enel. Alguns dias depois, fomos à zona sul acompanhar o trabalho de Júlio e com ele encontramos Carlos, morador de uma das ruas com mais pontos cegos de luz. Júlio começou uma longa conversa, tentando explicar o andamento da solicitação, mas foi uma comunicação bastante difícil, confusa, truncada pela própria natureza do problema e pela forma como os atores atuavam: a Enel, sem que Júlio soubesse, esteve na rua no dia posterior à reunião retirando os cabos de energia e postes. Isso gerou confusão entre os moradores, que viram ser retirado o que, mesmo que parcialmente, havia sido instalado.

Somente com uma certa suspensão analítica é possível entender como essa demanda por iluminação estava atravessada por decisões de outras instâncias, por problemas de governança dentro de um mesmo órgão e por limitações legais e espaços discricionários e não regulados: embora a liminar do juiz permitisse que a manutenção de postes (em que se enquadrava a instalação de lâmpadas) pudesse ocorrer, colocar lâmpada em postes antigos (que era o caso) não caracterizaria manutenção por questões de contrato da PPP. Seria preciso, então, mudar o poste, mas a mudança de poste extrapolaria o que se entende por manutenção. E, assim, os cabos foram retirados, mas novos cabos não foram instalados e Júlio enfrentou muita dificuldade em explicar isso aos moradores.

Esse é também um relato sobre a complexidade envolvida na implementação de uma política que raramente pode ser caracterizada como simples "entrega", e quase sempre é um conjunto (mais ou menos conforme as capacidades de coordenação e planejamento) encadeado de ações levadas adiante por distintas burocracias, suas ideias, interesses, instrumentos, regras etc. Esses cruzamentos e sobreposições deixam, muitas vezes, espaços não regulados ou situações não previstas. Nessas situações, brokers atuam como intermediários, tentando apresentar de baixo para cima o problema não (pre)visto pelas burocracias e, no sentido contrário, fazendo chegar a informação de cima para baixo. São atores politicamente motivados para isso, o que é bastante diferente de dizer que o voto condiciona a entrega da política.

Essa complexidade pode tornar bastante difícil a comunicação de procedimentos formais e de entraves institucionais de diversas ordens que uma demanda pode enfrentar. Como resumiu Júlio:

(...) e aí toda vez que eu falo com eles [moradores], passo carão, porque acham que a gente está de braço cruzado. Por isso que você viu naquela reunião lá, eu levei aquela quantidade de pessoas, eu sempre levo, um, dois de cada lugar pra eles verem a dificuldade que é negociar as coisas, porque eles acham que é fácil, entendeu? A situação que eles vivem também não é fácil, eu sei. 
Para não dizer que não falamos do período eleitoral

Júlio: Só estou te dando uma satisfação que nós estamos brigando lá [na Prefeitura].

Sr. Carlos: Vamos ver Júlio, que daqui a dois anos vai ter eleição de novo, só que a gente quer ter um acompanhamento, senão não dá.

Foi assim que terminou a conversa entre Júlio e o morador Carlos. Além de ilustrar à população em geral o desafio de comunicação de entraves judiciais e técnicos que atravancam o andamento de uma política, a fala de Carlos poderia sugerir uma vinculação entre indicações e eleições. Como vimos, esse é um argumento bastante comum na literatura, sobretudo quando se trata de recursos oriundos do orçamento público federal, como é o caso dos estudos sobre emendas individuais dos parlamentares. Com ou sem questionamentos ao argumento da conexão eleitoral, os testes se dão para verificar se os recursos públicos (mobilizados na forma de instrumentos como emendas) seriam usados por políticos como forma de conquistar eleitorado (testes medidos em termos de votos).

Ao explorar o argumento que o Sr. Carlos coloca para Júlio, não encontramos um padrão que vincule a intensidade de uso do instrumento ao ano eleitoral. Como evidencia o Gráfico 4 apresentado, não parece existir uma relação direta entre anos eleitorais (o último ano de cada legislatura) e o uso de indicações. Ao contrário, os anos eleitorais das cinco legislaturas analisadas são aqueles em que encontramos menor número de vereadores formalizando indicações junto à CMSP.

\section{Gráfico 4 \\ Número de vereadores que usaram indicações por ano}

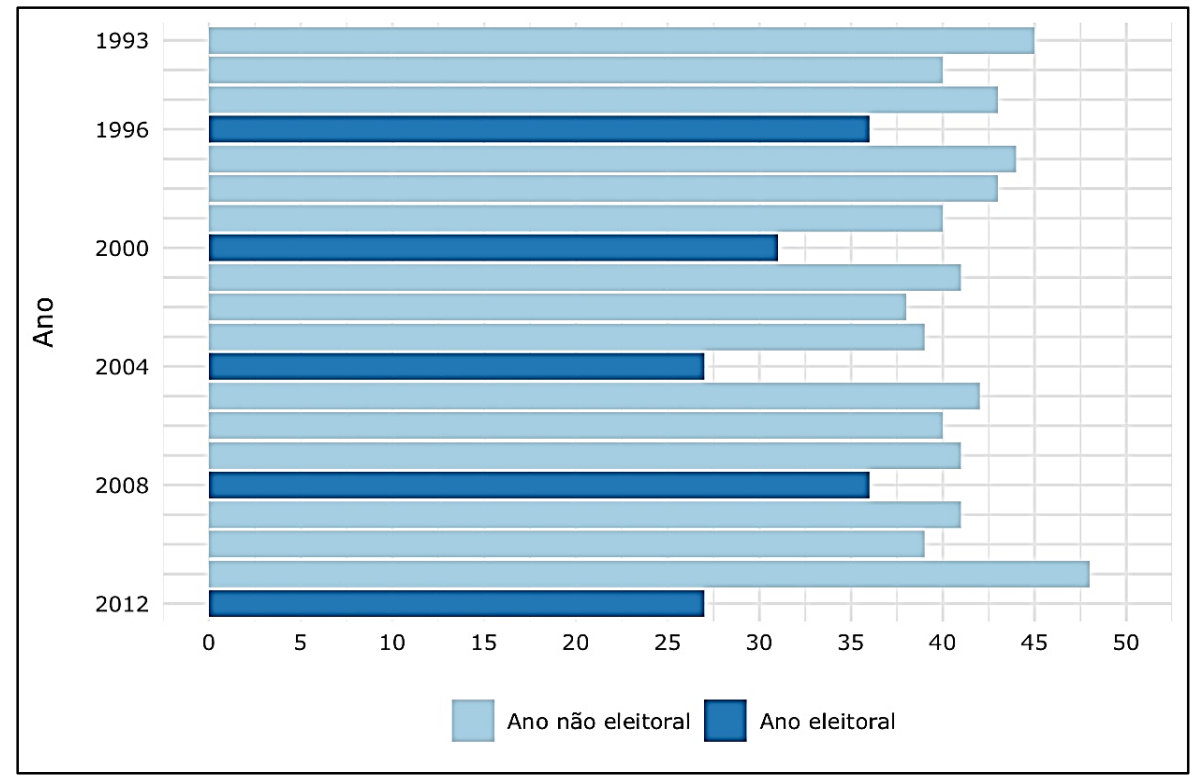

Fonte: Elaborado pelos autores a partir de dados da CMSP. 
Não afirmamos com isso que indicações não são uma estratégia eleitoral. A construção do vínculo entre brokers e a população tem, afinal, esse propósito. Procuramos mostrar que tanto o uso de mecanismos de construção do vínculo com o eleitor ao longo de todo o mandato (entre outros, as indicações) quanto a forma como isso se converte em voto são mais complexos do que temos suposto até aqui. Ou, pelo menos, que a metodologia adotada para fazer testes sobre a conexão eleitoral e os pressupostos da rational choice sobre a distribuição de políticas são insuficientes para captar a forma como se vinculam eleição e distribuição de políticas, o que produz voto e se existe ou não trabalho territorial.

As entrevistas apontam que, em anos eleitorais, ao contrário, a captura e a resolução de demandas por meio de indicações decrescem porque os brokers passam a se concentrar na montagem e na coordenação das equipes de campanha. Evidentemente, os brokers de um mandato não são suficientes para dar conta de uma campanha eleitoral, mas coordenam equipes contratadas para fazer campanha e distribuir material promocional do candidato. Em especial em regiões de baixa renda da cidade, esse é o momento em que aquelas pessoas que procuraram ajuda e se aproximaram do mandato durante os anos anteriores passam a atuar como brokers, no sentido de promover o vereador na sua rede de conhecidos e também desconhecidos, sendo contratadas para isso. Conforme essa pesquisa identificou, essas pessoas são escolhidas, preferencialmente, com base nos vínculos que o broker construiu ao longo do mandato. A relação de confiança é muito importante para evitar que as pessoas contratadas recebam dinheiro sem terem feito campanha, uma vez que se trata de um trabalho de difícil monitoramento (mensurar quanto estão se empenhando em divulgar o nome de um candidato e se de fato ficam nas ruas durante todo o período, por exemplo).

O caso de Attila Russomanno é mais uma vez uma excelente evidência em relação a esse ponto. Embora ele tenha protocolado volume impressionante de indicações e ainda adotado a estratégia de distribuí-las por toda a cidade, isso não resultou em votos suficientes para sua reeleição. Notícias da época33 apontam que ele teria pedido que seu partido interrompesse as remessas de material de campanha porque ele não tinha estrutura de pessoal suficiente para fazer a distribuição. No caso desse político, pela forma como foram utilizadas, as indicações não resultaram na construção de vínculos e, no momento da campanha, o candidato teve incrível dificuldade em montar suas equipes de divulgação eleitoral. Esse caso evidencia que a capacidade de converter o trabalho cotidiano em voto varia conforme estratégias adotadas em cada mandato, tornando o voto, visto isoladamente, uma proxy imperfeita para observação da complexidade da dinâmica de criação ou não de vínculos. Evidentemente, mais pesquisas precisam ser feitas para sustentar esse argumento, que é, na verdade, um ponto de chegada, não de partida, deste

33 Disponível em: <http://poderonline.ig.com.br/index.php/tag/attila-russomanno/>. Acesso em: 5 jan. 2020. 
artigo. Nossas evidências sugerem que os brokers são importantes elementos na montagem da estrutura de campanhas legislativas, e futuras análises precisam incorporar esses indivíduos nas explicações dessas dinâmicas.

\section{Considerações finais}

A literatura de ciência política aplica as análises feitas sobre os Poderes Executivo e Legislativo nacional na interpretação da lógica de funcionamento desses poderes no nível municipal. Nesse cenário teórico "emprestado", instrumentos e instituições próprias à lógica política local restam subexplorados ou não são levados em conta. Este artigo propõe uma inserção em sentido diferente. Com a perspectiva voltada à esfera local e partindo de uma combinação de métodos quantitativos e qualitativos, analisamos o processo pelo qual são feitas indicações pelo Poder Legislativo na cidade de São Paulo. Enquanto parte da literatura tem se desenvolvido no sentido da negação do trabalho territorial de vereadores, encontramos que: (i) as relações de políticos e cidadãos em São Paulo são construídas via brokers que atuam territorialmente; (ii) entre os instrumentos de atuação para a construção desses vínculos com eleitores, estão as indicações; (iii) existem clusters com alta incidência de indicações por um vereador ao longo de uma legislatura; e (iv) não há evidências de maior uso de indicações em anos eleitorais, sugerindo um mecanismo mais complexo para explicar o fenômeno da conexão eleitoral.

Indicações são distribuídas de forma relativamente esparsa na cidade, o que, a princípio, parece contrastar com as evidências qualitativas do uso das indicações para a construção do vínculo entre eleitores e políticos. Entretanto, uma análise mais detida revela que, a despeito das largas distâncias entre as indicações, estas formam clusters ao longo do território, reforçando que, nos locais em que vereadores têm apoio dos brokers, as indicações tendem a ser protocoladas com mais frequência que nos demais.

Há, ainda, um vasto campo a ser explorado para compreender os mecanismos de criação desses vínculos, como isso se relaciona às equipes de campanhas e aos padrões de votação, bem como os desafios de implementação de políticas e a razão pela qual os brokers aparecem como atores essenciais para que algumas políticas cheguem a territórios periféricos da cidade. Para nos aproximarmos dessas respostas, seguimos defendendo a combinação de métodos e também a ponte entre referenciais teóricos - nesse caso, aliando aos estudos legislativos e à discussão sobre conexão eleitoral o debate sobre burocracias e políticas públicas - como caminho profícuo de investigação.

\section{Referências bibliográficas}

AMES, B. "Electoral strategy under open-list proportional representation". American Journal of Political Science, vol. 39, no 2, p. 406-433, 1995. 
AMES, B. Os entraves da democracia no Brasil. Rio de Janeiro: Editora FGV, 2003.

Amorim Neto, O.; SANTOS, F. "O segredo ineficiente revisto: o que propõem e o que aprovam os deputados brasileiros". Dados, vol. 46, no 4, p. 449-479, 2003.

ANSELIN, L. "Local indicators of spatial association". Geographical Analysis, vol. 27, no 2, p. 93-115, abr. 1995.

ARBIA, G.; ESPA, G.; GIULIANI, D. Analysis of spatial concentration and dispersion. In: KARLSSON, C.; ANDERSSON, M.; NORMAN, T. (orgs.). Handbook of research methods and applications in economic geography. Cheltenham, Reino Unido; Northampton, EUA: Edward Elgar Publishing, p. 135-157, 2015.

Avelino, G.; Biderman, C.; Silva, G. P. "A concentração eleitoral no Brasil (1994-2014)". Dados, vol. 59, no 4, p. 1.091-1.125, 2016.

AYUERO, J. "Performing Evita: a tale of two peronist women". Journal of Contemporary Ethnography vol. 27, no 4, p. 461-493, 1999.

. "The logic of clientelism in Argentina: an ethnographic account". Latin American Research Review, vol. 35, no 3, p. 55-81, 2000.

BARONE, L. S. "Eleições, partidos e política orçamentária no Brasil: explorando os efeitos das eleições locais na política nacional". Tese de Doutorado em Administração Pública e Governo. Fundação Getúlio Vargas, Eaesp, São Paulo, 2014.

BAstos, G. "O clientelismo político e o joio e o trigo da política municipal". Dissertação de Mestrado no Programa de Pós-Graduação em Ciências Sociais. Universidade Federal de Juiz de Fora, Juiz de Fora, 2017.

BivAND, R. S.; WONG, D. W. S. "Comparing implementations of global and local indicators of spatial association". Test, vol. 27, no 3, p. 716-748, 2018.

Bivand, R. S.; Pebesma, E.; Gómez-Rubio, V. Applied spatial data analysis with R. New York: Springer, 2013.

Brusco, V.; Nazareno, M.; Stokes, S. "Vote buying in Argentina". Latin American Research Review, vol. 39, no 2, p. 66-88, 2004.

CAETANo, B. "Executivo e Legislativo na esfera local: agenda e construção de maiorias na Câmara Municipal de São Paulo". Novos Estudos - Cebrap, vol. 71, p. 101-125, 2005.

Calvo, E.; Murillo, M. "Who delivers? Partisan clients in the Argentine electoral market". American Journal of Political Science, vol. 48, no 4, p. 742-757, 2004.

ChARRAD, M.; et al. "NbClust: an R Package for determining the relevant number of clusters in a data set". Journal of Statistical Software, vol. 61, nº 6, 2014.

CORRÊA, F. "O que fazer para sobreviver politicamente? Padrões de carreira dos deputados estaduais no Brasil". Tese de Doutorado em Ciência Política. Universidade Federal de Minas Gerais, Belo Horizonte, 2016.

DARMOFAL, D. Spatial analysis for the social sciences. New York, NY: Cambridge University Press, 2015.

D'Ávila, P. M. F.; Cerqueira LimA, P. C. G.; Jorge, V. "Indicação e intermediação de interesses: uma análise da conexão eleitoral na cidade do Rio de Janeiro, 2001-2004". Revista de Sociologia e 
Política, vol. 22, no 49, p. 39-60, 2014.

DiXIT, A.; LONDREGAN, J. "The determinants of success of special interests in redistributive politics". The Journal of Politics, vol. 58, no 4, p. 1.132-1.155, 1996.

Figueiredo, A.; Limongi, F. Executivo e Legislativo na nova ordem constitucional. São Paulo: Fundação Getulio Vargas Editora, 1999.

FINAN, F.; SCHECHTER, L. "Vote-buying and reciprocity". Econometrica, vol. 80, no 2, p. 863-881, 2012.

FirPo, S.; PonCZeK, V.; SANFelice, V. "The relationship between federal budget amendments and local electoral power". Journal of Development Economics, vol. 116, p. 186-198, 2015.

FREY, A. "Cash transfers, clientelism, and political enfranchisement: evidence from Brazil". Journal of Public Economics, vol. 176, p. 1-17, 2019.

Gallego, J.; LI, C.; WANTCHEKON, L. "The political economy of patrons, brokers, and voters". Documentos de Trabajo 016547, Universidad del Rosario, 2018. Disponível em: <https://ideas.repec.org/p/col/000092/016547.html>. Acesso em: 5 jan. 2020.

GeLAPE, L. O. "A geografia do voto em eleições municipais no sistema eleitoral de lista aberta: um estudo a partir de Belo Horizonte, Rio de Janeiro e São Paulo". Dissertação de Mestrado em Ciência Política. Universidade Federal de Minas Gerais. Belo Horizonte, 2017.

GONÇALVES, R. D. "Onde agrego os votos? Contribuições à geografia eleitoral aplicada a problemas político-eleitorais brasileiros". Dissertação de Mestrado em Ciência Política. Universidade Federal do Paraná, Curitiba, 2016.

GRIN, E. "Construção e desconstrução das subprefeituras na cidade de São Paulo no governo Marta Suplicy". Revista de Sociologia e Política, vol. 23, n 55, p. 119-145, 2015.

Gun, L. "Why is implementation so difficult?". Management Services in Government, vol. 33, p. 169179, 1978.

Gun, L.; Hogwood, B. Models of policy-making. Centre for the Study of Public Policy. Glasgow: University of Strathclyde, 1982.

HAGOPIAN, F. Parties and voters in emerging democracies. In: BOIX, C.; STOKES, S. The Oxford handbook of comparative politics. Oxford; New York: Oxford University Press, p. 582-603, 2009.

KInZO, M. D.; BORIN, I.; MARTINS JR., B. "Padrões de competição eleitoral na disputa para a Câmara paulistana: 1992-2000". Novos Estudos - Cebrap, vol. 65, p. 45-56, 2003.

KITSCHELT, H. "Linkages between citizens and politicians in democratic polities". Comparative Political Studies, vol. 33, no 6-7, p. 845-879, 2000.

KITSCHELT, H.; WILKINSON, S. Citizen-politician linkages: an introduction. In: KITSCHELT, H.; WiLKINSON, S. (eds.). Patrons, clients, and policies: patterns of democratic accountability and political competition. Cambridge: Cambridge University Press, p. 1-49, 2007.

KUSCHNIR, K. O cotidiano da política. Rio de Janeiro: Zahar Editora, 2000.

LIMA, F. "Committed brokers: a união entre prefeitos e deputados no Brasil". Tese de Doutorado em Ciência Política. Universidade Federal de Minas Gerais. Belo Horizonte, 2016.

LimONGi, F.; Figueiredo, A. "Processo orçamentário e comportamento legislativo: emendas 
individuais, apoio ao Executivo e programas de governo". Dados, vol. 48, no 4, p. 737-776, 2005.

Mainwaring, S. Sistemas partidários em novas democracias: o caso do Brasil. Porto Alegre; Rio de Janeiro: Mercado Aberto; Editora FGV, 2001.

MARques, E. C. L. (org.). A metrópole de São Paulo no século XXI: espaços, heterogeneidades e desigualdades. São Paulo: Editora Unesp, 2015.

. "Em busca de um objeto esquecido: a política e as políticas do urbano no Brasil". Revista Brasileira de Ciências Sociais, vol. 32, no 95, 2017.

MesquitA, L. "Emendas ao orçamento e conexão eleitoral na Câmara dos Deputados brasileira". Dissertação de Mestrado em Ciência Política. Universidade de São Paulo. São Paulo, 2008.

MESQUITA, L., et al. "Emendas individuais e concentração de votos: uma análise exploratória". Teoria e Pesquisa, vol. 23, no 2, p. 82-106, 2014.

Neto, J. O Legislativo e o poder local. In: Benevides, M. V.; Kerche, F.; Vanucchi, P. (orgs.). Reforma política e cidadania. São Paulo: Perseu Abramo, 2003.

NiCHTER, S. "Vote buying or turnout buying? Machine politics and the secret ballot". The American Political Science Review, vol. 102, no 1, p. 19-31, 2018.

Novaes, L. M. "Disloyal brokers and weak parties". American Journal of Political Science, vol. 62, nº 1 , p. 84-98, 2018.

Oliveros, V. "Making it personal: clientelism, favors, and the personalization of public administration in Argentina". Comparative Politics, vol. 48, n 3, p. 373-391, 2016.

Pereira, C.; Mueller, B. "Partidos fracos na arena eleitoral e partidos fortes na arena legislativa: a conexão eleitoral no Brasil". Dados, vol. 46, no 4, p. 735-771, 2003.

Pressman, J.; Wildavsky, A. Implementation. Berkeley: University of California Press, 1973.

RANGel, A. "Produção parlamentar municipal: os projetos de indicação". Caderno Eletrônico de Ciências Sociais, Vitória, vol. 2, no 1, p. 113-132, 2014.

RiccI, P. "De onde vêm nossas leis? Origem e conteúdo da legislação em perspectiva comparada". Tese de Doutorado no Programa de Pós-Graduação em Ciência Política. Universidade de São Paulo, São Paulo, 2006.

RochA, M.; SILVA, B. "O poder de indicar: preferências legislativas de vereadores mineiros". Cadernos Adenauer, vol. XVIII, no 2, p. 185-208, 2017.

SChAFFER, J.; BAKER, A. "Clientelism as persuasion-buying: evidence from Latin America". Comparative Political Studies, vol. 48, no 9, p. 1.093-1.126, 2015.

SCHWARTZ-SHEA, P.; MAJIC, S. "Ethnography and participant observation: political science research in this 'late methodological moment"'. PS: Political Science \& Politics, vol. 50, n 1, p. 97-102, 2017.

SILVA, P. "O poder legislativo municipal, estrutura, composição e produção". Dissertação de Mestrado no Programa de Pós-Graduação em Ciência Política, Universidade de São Paulo, São Paulo, 2014.

STOKES, S. "Perverse accountability: a formal model of machine politics with evidence from Argentina". American Political Science Review, vol. 9, no 3, p. 315-325, 2005.

Stokes, S. C., et al. Brokers, voters, and clientelism. Cambridge: Cambridge University Press, 2013. 
TAN, P., et al. Introduction to data mining. $2^{\circ}$ ed. New York: Pearson, 2019.

VASSELAI, F.; MignOZZETTI, U. G. "O efeito das emendas ao orçamento no comportamento parlamentar e a dimensão temporal: velhas teses, novos testes". Dados, vol. 57, no 3, p. 817-853, 2014.

WILDAVSKY, A. Speaking truth to power: the art and craft of policy analysis. Little Brown: Boston, 1979.

ZARAZAGA, S. J. R. "Brokers beyond clientelism: a new perspective through the Argentine case". Latin American Politics and Society, vol. 56, no 3, p. 23-45, 2014.

\section{Apêndice - Ofício de indicação e folha de solicitação}

Figura 1A

Exemplo de ofício de indicação - São Paulo

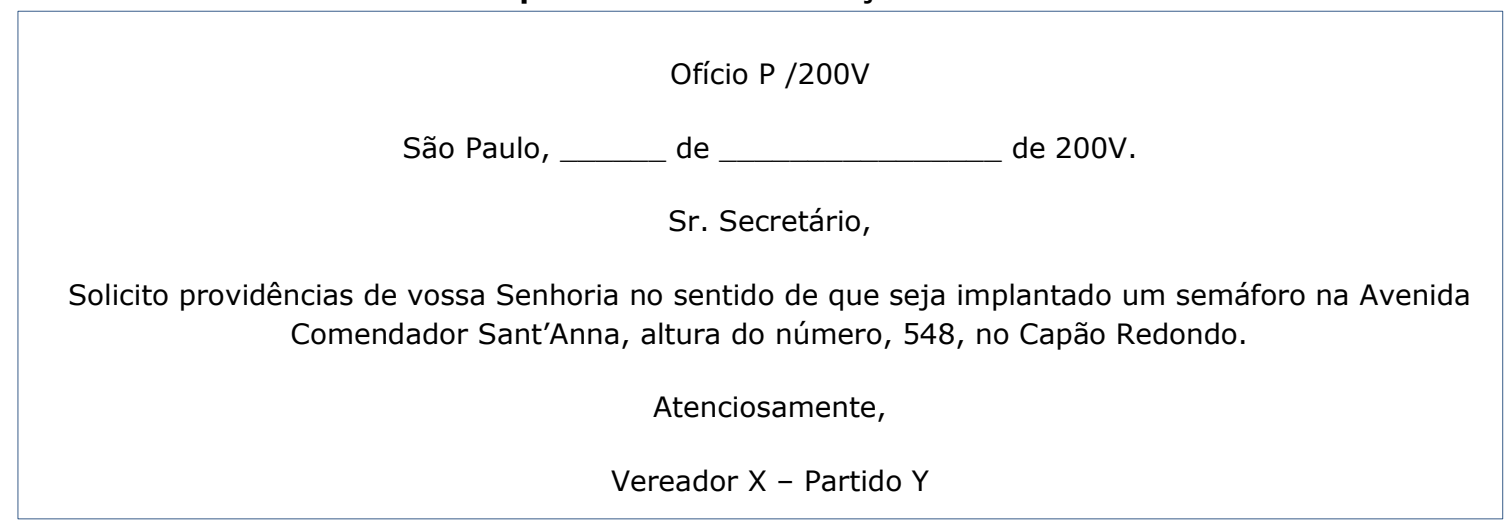

Fonte: Elaboração própria com base em documentos oficiais. 
Figura 2A

Folha de solicitação a ser preenchida pelo broker junto à população

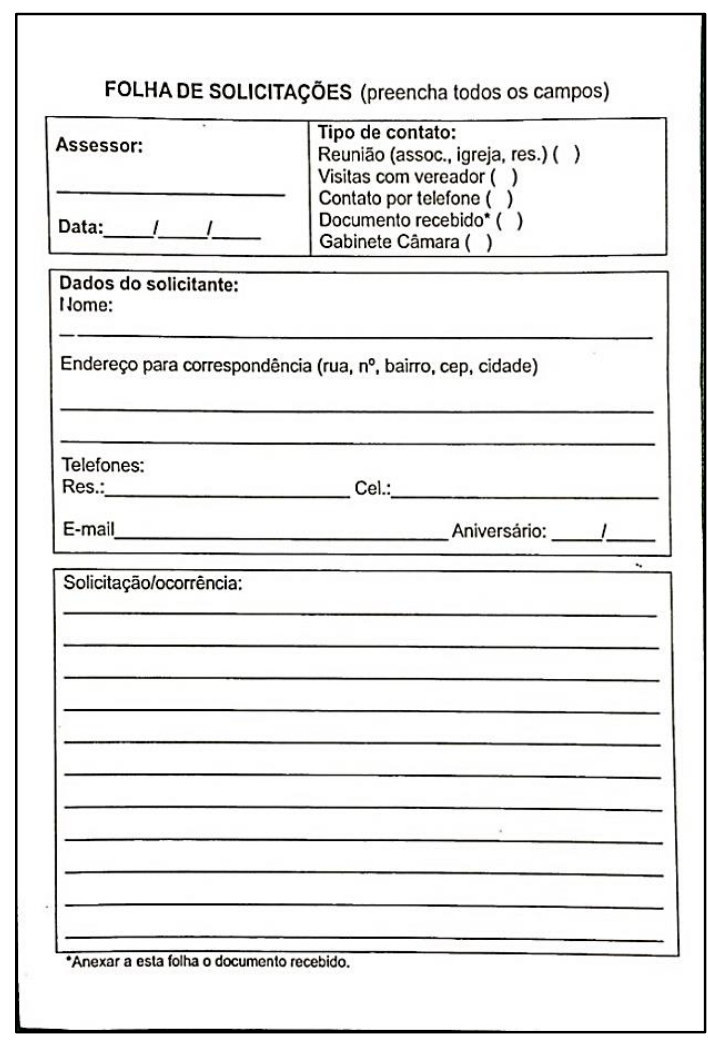

Fonte: Documento elaborado pelo mandato de um vereador.

\section{Abstract}

The construction of political-territorial ties: evidence from of São Paulo

Current interpretations on the inner workings of Brazilian city councils are rooted in the scholarly debate of national politics. In the latter, the presence of legislation proposals with territorial goals and concentrated electoral voting patterns are the main evidence of distributivism/clientelism. We argue, however, that such characteristics of legislative and electoral politics at the national level are ill-suited proxies for analysis of the local level, failing to capture nuances of political mobilization in cities. Instead, by means of a mixed-methods analysis of an instrument called representatives' requests in-depth interviews, participant observation, and local spatial autocorrelation hypothesis tests - we argue that city councilors' geographically targeted actions take place through a capillary and rooted structure of brokers that feeds back and creates ties throughout local mandates and voters.

Keywords: brokers; city councilors; territorial ties; representatives' requests; city council

\section{Resumen}

La construcción de vínculos político-territoriales en la ciudad: el caso de São Paulo

Las interpretaciones actuales sobre el funcionamiento interno de los concejos municipales en Brasil provienen de los debates académicos centrados en la política nacional. Para estos, la evidencia 
principal del distributismo/clientelismo es tanto la presencia de propuestas legislativas con objetivos territoriales, como los patrones de concentración del voto electoral. Sin embargo, nosotros argumentamos que dichas características procedentes de la política legislativa y electoral a nivel nacional son aproximaciones poco adecuadas para analizar el nivel local, ya que no captan los matices de la movilización política en las ciudades. En su lugar, mediante el análisis de un instrumento llamado peticiones legislativas a través de métodos mixtos (entrevistas detalladas, observación de participantes y pruebas de hipótesis de autocorrelación espacial-local), argumentamos que las acciones geolocalizadas de los consejeros municipales tienen lugar mediante una estructura capilar y arraigada de intermediarios (brokers), que se retroalimenta y crea vínculos a través de los mandatos y los votantes locales.

Palabras clave: brokers; consejeros municipales; vínculos territoriales; peticiones legislativas; concejo municipal

\section{Résumé}

La construction de liens politiques territoriaux dans le ville: Le cas de São Paulo

$\mathrm{Au}$ Brésil, les législatures municipales ont été étudiées à partir d'une transposition théoricoargumentative de la politique fédérale, en portant une attention privilégiée aux projets de lois et au modèle de distribution des votes dans la mise en mise en évidence de logiques distributives / clientélistes. Toutefois, il s'agit-là de proxis imparfaits pour rendre compte de la performance territoriale des conseillers. Pour étudier le sujet à São Paulo, nous introduisons l'analyse d'un instrument appelé "indication parlementaire", ainsi que son étude à partir d'une approche multiméthodes, comprenant des entretiens approfondis, l'observation participante et des tests d'hypothèse d'autocorrélation spatiale locale. Nous soutenons que la performance territoriale des conseillers passe par une structure capillaire de brokerage qui construit des liens tout au long du mandat. Cette réalité ne peut être saisie tant par les méthodes traditionnelles que par les approches par le clientélisme.

Mots-clés: brokers; conseillers municipaux; liens territoriaux; indications parlementaires; législature municipale 